\title{
Cannabinoids Reveal the Necessity of Hippocampal Neural Encoding for Short-Term Memory in Rats
}

\author{
Robert E. Hampson and Sam A. Deadwyler \\ Department of Physiology and Pharmacology and Center for Neurobiological Investigation of Drug Abuse, Wake Forest \\ University School of Medicine, Winston Salem, North Carolina 27157
}

The memory-disruptive effects of $\Delta^{9}$-tetrahydrocannabinol $\left(\Delta^{9}\right.$ THC) and the synthetic cannabinoid WIN 55,212-2 (WIN-2) were assessed in rats exposed to varying doses of each drug $\left(\Delta^{9}-\mathrm{THC}\right.$, $0.5-2.0 \mathrm{mg} / \mathrm{kg}$; WIN-2, 0.25-0.75 mg/kg) during performance of a delayed nonmatch to sample (DNMS) task. Cannabinoids affected performance in a dose $\times$ delay-dependent manner, with WIN-2 showing a potency more than four times that of $\Delta^{9}-\mathrm{THC}$. These effects on DNMS performance were eliminated if the cannabinoid CB1 receptor antagonist SR141617A (Sanofi Research Inc.) was preadministered, but doses of the antagonist alone had no effect on performance. Simultaneous recording from ensembles of hippocampal neurons revealed that both WIN-2 and $\Delta^{9}$-THC produced dose-dependent reductions in the frequency (i.e.,"strength") of ensemble firing during the sample phase of the task to the extent that performance was at risk for errors on $>70 \%$ of trials as a function of delay. This decrease in ensemble firing in the Sample phase resulted from selective interference with the activity of differentiated hippocampal functional cell types, which conjunctively encoded different combinations of task events. A reduction in ensemble firing strength did not occur in the nonmatch phase of the task. The findings indicate that activation of $\mathrm{CB} 1$ receptors renders animals at risk for retention of item-specific information in much the same manner as hippocampal removal.

Key words: cannabinoids; memory; hippocampus; neural ensembles; encoding; dose dependence; agonists/antagonists
The precise role of the mammalian hippocampus in the processing of memory has evolved considerably since initial reports some 40 years ago (Scoville and Milner, 1957) showing retention deficits in humans after damage to the medial temporal lobe and related structures (Milner, 1972; Zola-Morgan et al., 1986; Warrington and Duchen, 1992; Mishkin et al., 1998). Early studies in animals showed that lesions of hippocampus impaired performance in delay tasks (Correll and Scoville, 1965; Olton and Feustle, 1981; Rawlins, 1985; Parkinson et al., 1988; Raffaele and Olton, 1988). However, later studies demonstrated that many of these deficits resulted from retrohippocampal damage, and performance was not impaired by ibotenate lesions confined to the dentate gyrus and CA1 and CA3 subfields (Jarrard, 1993; Rawlins et al., 1993). In rodents, it is also clear that hippocampal lesions impair spatial short-term memory (Angeli et al., 1993; Cho and Jaffard, 1995). We have recently shown that selective hippocampal removal impairs performance of a spatial delayed nonmatch to sample (DNMS) task in rodents (Hampson et al., 1999a). Similar but completely reversible memory impairment occurs in the same task with activation of cannabinoid receptors by marijuana derivatives or synthetic ligands (Hampson and Deadwyler, 1998a).

The role of cannabinoids in memory processes can be traced to early observations in humans, which documented significant disruption of short-term recall as the most consistent disruptive effect of marijuana intoxication (Miller and Branconnier, 1983). More recent investigations have confirmed that the effects of $\Delta^{9}$ tetrahydrocannabinol $\left(\Delta^{9}\right.$-THC; a principal psychoactive agent in marijuana) include perceptual and disorienting effects in addition to memory disruption (Chait and Pierri, 1992). Perhaps the most intriguing finding with respect to cannabinoid receptor actions in hippocampus is the observation that cannabinoids impair memory by selectively disrupting the processing (encoding) of information to be recalled on a particular trial (Hampson et al., 1993; Heyser et

Received Feb. 1, 2000; revised Sept. 18, 2000; accepted Sept. 20, 2000

This work was supported by National Institutes of Health Grants DA08549 to R.E.H. and DA00119 and DA03502 to S.A.D.

Correspondence should be addressed to Dr. Sam A. Deadwyler, Department of Physiology and Pharmacology, Wake Forest University School of Medicine, Winston Salem, NC 27157. E-mail: sdeadwyl@wfubmc.edu.

Copyright (C) 2000 Society for Neuroscience $0270-6474 / 00 / 208932-11 \$ 15.00 / 0$ al., 1993). This disruption in short-term memory occurs because the hippocampus is one of the areas in the brain with high densities of cannabinoid receptors (Herkenham et al., 1990), which were shown recently to be located on the terminals of GABAergic interneurons (Tsou et al., 1998; Katona et al., 1999). In addition, cannabinoids reduce glutamatergic synaptic transmission onto hippocampal neurons in culture (Shen et al., 1996), which occurs via a presynaptic mechanism on hippocampal principal cells (Misner and Sullivan 1999) and interneurons (Hoffman and Lupica, 2000). These observations are also consistent with reports suggesting that linkages of cannabinoid actions to intracellular mechanisms inhibit or reduce neural transmission within hippocampal circuits (Mackie and Hille, 1992; Deadwyler et al., 1993, 1995; Twitchell et al., 1997; Hoffman and Lupica, 2000). From recent insights gained through multineuron (ensemble) recording in intact animals to delineate the nature of hippocampal information processing in the DNMS task (Deadwyler et al., 1996), we now report that cannabinoids appear to act selectively to disrupt encoding of events in hippocampus during memory processing.

\section{MATERIALS AND METHODS}

Subjects. Sixteen $(n=16)$ male Long-Evans rats ranging in age from 200 to $250 \mathrm{~d}$ were used as subjects. All animals were trained to the same DNMS performance criteria ( $90 \%$ at $1-5 \mathrm{sec}$ delays) before surgery was performed and retrained to that criteria after surgery and before testing commenced.

Apparatus. The apparatus was similar to that used in other studies from this laboratory (Hampson et al., 1993; Heyser et al., 1993; Deadwyler et al., 1996), which consisted of a $43 \times 43 \times 53 \mathrm{~cm}$ Plexiglas behavioral testing chamber with two levers mounted on either side of a water trough on the same wall and a nose poke device mounted in the center of the opposite wall. The entire apparatus was housed inside a commercially built soundattenuated cubicle (Industrial Acoustics Co., Bronx, NY). The two retractable levers (Coulborn Instruments, Lehigh Valley, PA) were positioned 3.5 $\mathrm{cm}$ above the floor and separated $14.0 \mathrm{~cm}$ center to center. The nose poke device, consisting of an infrared photodetector and light-emitting diode spanning a $2.5 \times 1 \times 1 \mathrm{~cm}$ opening in an aluminum housing, was mounted $4.0 \mathrm{~cm}$ above the chamber floor, centered on the wall opposite the levers. A cue light $(6 \mathrm{~V}, 10 \mathrm{~W})$ was positioned immediately above the nose poke device, and a speaker mounted overhead provided constant $85 \mathrm{db}$ "white noise." Two $12 \mathrm{~V}, 25 \mathrm{~W}$ incandescent lamps (house lights) were mounted on the top of the chamber. Video monitoring and computer tracking of the animal at all times was provided by a Sanyo CCD black-and-white video camera mounted above the chamber. The apparatus was controlled by 
personal computers, which collected all behavioral data and stored it on magnetic disks.

Behavioral training procedure. Animals were water-deprived and allowed access to food for maintenance at $85-90 \%$ ad libitum weight throughout DNMS training and testing. Animals received water daily after the behavioral session; hence, before each behavioral session animals were typically water-deprived for 20-22 hr. Periodically (every 30-60 d) animals were taken off the deprivation schedule and given access to water and food $a d$ libitum, and a new weight was calculated to permit normal body growth.

The DNMS task and pretraining were identical to those described by Deadwyler et al. (1996), which consisted of three main phases, sample, delay, and nonmatch. At the initiation of a trial (sample phase), either the left or right lever was extended [sample presentation (SP)] at a 50\% overall probability, and the animal responded [sample response (SR)]. The lever was immediately retracted, and the delay phase was initiated, signaled by the presence of the illuminated cue light over the nosepoke device. The duration of the delay phase varied randomly on any given trial between 1 and $30 \mathrm{sec}(1.0 \mathrm{sec}$ resolution) with equal likelihood for any duration. The animal was required to nose poke in the photocell device on the opposite wall at least once during the delay interval (variable interval schedule of 60 $\mathrm{sec})$. The last nose poke after the delay interval timed out turned off the cue light and extended both levers. The presence of both levers signaled the onset of the nonmatch phase of the task in which the animal was required to press the lever opposite to the SR (Sample phase), constituting the nonmatch response (NR). Water was delivered immediately to the trough between the two levers if the animal performed correctly. The levers were then immediately retracted for $10 \mathrm{sec}$ [intertrial interval (ITI), $10 \mathrm{sec}$, at which time another trial was initiated by extension of a single lever. On incorrect (error) trials in which an inappropriate (i.e., "match") lever press occurred, an immediate $5 \mathrm{sec}$ time-out (TO) period was initiated in which the house lights were turned off, leaving the chamber completely dark and both levers retracted. After the time-out period, the lights were turned back on for an additional $5 \mathrm{sec}$ with no levers available $(\mathrm{TO}+5 \mathrm{sec}=$ ITI, $10 \mathrm{sec}$, after error trials $)$.

The average time required to train a naive animal to criterion in the DNMS task with $1-30$ sec delays was $\sim 3-4$ weeks. Training involved several phases in which different procedures were used to develop selective responding on each lever, stimulus control over nose poke responding during the delay, and linkage of responding in the sample and nonmatch phases of the task. A final criterion of $90-95 \%$ correct responding on trials with delays of 1-5 sec during sessions consisting of 1-30 delay trials was used for all animals (Hampson et al., 1993; Deadwyler et al., 1996).

Drug preparation and administration. $\Delta^{9}$-THC and WIN55, 212-2 (WIN-2) were prepared for injection using the same vehicle. $\Delta^{9}$-THC was obtained from the National Institute on Drug Abuse as a $50 \mathrm{mg} / \mathrm{ml}$ solution in ethanol. WIN-2 was purchased from Research Biochemicals (Natick, MA) as mesylate powder and dissolved in ethanol to a make a $20 \mathrm{mg} / \mathrm{ml}$ stock. Detergent vehicle was prepared from Pluronic F68 (Sigma, St. Louis, MO), $20 \mathrm{mg} / \mathrm{ml}$ in ethanol. Cannabinoids were added to the detergent-ethanol solution $(0.5 \mathrm{ml}$ of either THC or WIN-2), and then 2.0 $\mathrm{ml}$ of saline $(0.9 \%)$ was slowly added to the ethanol-drug solution. The solution was stirred rapidly and placed under a steady stream of nitrogen gas to evaporate the ethanol $(\sim 10 \mathrm{~min})$. This resulted in a detergent-drug suspension $(12.5 \mathrm{mg} / \mathrm{ml} \mathrm{THC}$ or $5.0 \mathrm{mg} / \mathrm{ml} \mathrm{W} \mathrm{IN-2)}$, which was sonicated and then diluted with saline to final injection concentrations $(0.5-2.0$ $\mathrm{mg} / \mathrm{ml} \mathrm{THC}$ and $0.25-0.75 \mathrm{mg} / \mathrm{ml} \mathrm{WIN-2,} \mathrm{pH} \mathrm{7.2).} \mathrm{Vehicle} \mathrm{solutions} \mathrm{were}$ prepared in a similar manner, except the drug was omitted. The CB1 receptor antagonist SR141716A (Sanofi Research Inc.) was prepared in the same manner. On drug administration days, animals were injected intraperitoneally with the drug-detergent solution $(1 \mathrm{ml} / \mathrm{kg}) \sim 10 \mathrm{~min}$ before the start of the behavioral session. On vehicle-only days (control), the vehicle solution was administered at $1.0 \mathrm{ml} / \mathrm{kg} 10 \mathrm{~min}$ before the start of the session. When SR141716A was administered in the same session as $\Delta^{9}$ THC or WIN-2, it was injected intraperitoneally $10 \mathrm{~min}$ before the cannabinoid. When administered alone, SR141716A was injected 20 min before the start of the behavioral session. At least $2 \mathrm{~d}$ of vehicle-only injections were imposed between each drug-testing session. All drug solutions were mixed fresh each day.

Analyses of behavioral data. Behavioral data consisted of several different measures designed to elucidate different DNMS performance factors. The two primary measures used were mean percent correct trials during the session and mean percent correct trials at each delay interval assessed in $5.0 \mathrm{sec}$ blocks. Additional measures included time of execution of the trial and influence of previous trial delay. ANOVA was used for most comparisons with adjusted pairwise contrasts used for individual comparisons and simple effects. Trial-to-trial influences were examined by various methods of sorting the data as a function of performance on the previous trial, delay intervals on any given trial, or electrophysiological variables.

Surgery. As animals reached behavioral performance criterion on the DNMS task, they were surgically implanted with multineuron recording arrays that consisted of a sixteen $40 \mu \mathrm{m}$ wire electrodes (NBLabs, Denison, TX) aimed at the CA1 and CA3 subfields of the hippocampus (Deadwyler et al., 1996). Eight animals received array implants in this study; the others were not implanted. Animals were anesthetized with ketamine $(100 \mathrm{mg} / \mathrm{kg})$ and xylazine $(10 \mathrm{mg} / \mathrm{kg})$ during the procedure. The array was positioned at the time of surgery with the tips of the electrodes above or within the cell layers of the CA1 and CA3 subfields of the hippocampus. The center pair of array electrodes was positioned at coordinates $3.8 \mathrm{~mm}$ posterior to bregma and $3.0 \mathrm{~mm}$ left of midline. The longitudinal axis of the area was angled $30^{\circ}$ midline, with posterior electrode sites more lateral than anterior sites. The array was driven in 25-100 $\mu \mathrm{m}$ steps to a depth of $3.0-4.0 \mathrm{~mm}$ for CA3 leads, with the CA1 leads automatically positioned 1.2-1.4 $\mathrm{mm}$ higher. Neural activity from the microwire electrodes was monitored throughout surgery to ensure placement in appropriate hippocampal cell layers. After array placement, the cranium was sealed with bone wax and dental cement, and the animal was allowed to recover for at least 1 week. The scalp wound was treated periodically with Neosporin antibiotic, and animals were given an injection of Crysticillin (penicillin G, 300,000 U) to prevent infection. All animal care and experimental procedures conformed to National Institutes of Health and Society for Neuroscience guidelines for care and use of experimental animals.

Multineuron recording technique. Neural activity (extracellular action potentials, or "spikes") and behavioral responses were digitized and timestamped for computer processing, as were all behavioral events within each DNMS trial. Single neurons recorded on each wire of the array were isolated and selected for analysis from the 16 different locations on the recording array. Only one neuron from each electrode wire was included in the analysis of ensemble data. Neuronal action potentials were digitized at $40 \mathrm{kHz}$ and isolated by time-amplitude window discrimination as well as computer-identified individual waveform characteristics via a Spike Sorter (Plexon, Dallas, TX). Identified spikes from selected wires were "tracked" from session to session by waveform and firing characteristics within the task (perievent histograms), and only spike waveforms with associated firing rates consistent with behavioral correlates across sessions were included in the analysis. The likelihood that the same neurons were not continuously recorded under these conditions given the above identifying criteria was considered extremely low (Hampson et al., 1996).

Ensemble analysis. Changes in neural firing rates were analyzed for statistically significant differences by two- and three-way ANOVA. Measurements of single neuron firing rate included mean \pm SEM firing rate within defined intervals (i.e., across delays in 5-10 sec blocks), mean firing rate before, during, and after fixed behavioral events (i.e., $\pm 1.5 \mathrm{sec}$ for SR or NR), and peak firing rate during the sample, delay, and nonmatch phases. Standard scores $[Z=$ (peak rate - background rate)/SD] were computed to determine significant peak firing rates at the behavioral events. Using this measure, $92 \%$ of cells recorded showed firing correlates to the DNMS behavioral events. The background firing rate was computed from $3 \mathrm{sec}$ intervals during the ITI.

Combined simultaneous multineuron firing rates were also analyzed by multivariate statistical procedures. Canonical discriminant analyses (CDAs) were performed on ensemble data sets in accordance with procedures published previously (Hampson and Deadwyler, 1998b). Briefly, firing rates within 12 bins of $250 \mathrm{msec}$ duration surrounding each identified behavioral event were recorded for each ensemble on a trial-by-trial basis. These firing rates were used to compute neuron-by-time cross-covariance matrices for each ensemble at each behavioral event. The eigenvalues and eigenvectors of the matrix were then derived and correlated to the classification variables (behavioral events). Canonical discriminant functions (eigenvectors) were then identified that correlated to task-relevant information across different dimensions of the task (i.e., task phase and lever position). The most significant derived discriminant functions (DFs) in the task were then calculated continuously at $3 \mathrm{sec}$ intervals throughout the trial to determine the nature of identified variance at different times during the trial. This "sliding" CDA allowed detection of fluctuations in the sources of variability across the trial within each ensemble (Hampson et al., 1999a). Individual neurons making up these DFs were then identified as functional cell types (FCTs), which served as the basis for examining the effects of cannabinoids on processing at the cellular as well as ensemble level. Hippocampal FCTs were sorted into their respective categories and were considered to encode the event if the firing rate exceeded a $Z$ score of $3.19(p<0.001)$. Cell locations were then mapped onto a composite CA3-CA1 fold-out map of relative electrode locations along the array (Hampson et al., 1999b).

\section{RESULTS}

\section{Influence of cannabinoids on DNMS behavior}

Behavioral performance in the DNMS task was measured in 13 Long-Evans rats trained to the criterion and then exposed to four different doses of $\Delta^{9}$-THC or WIN-2. Normal DNMS performance (Fig. 1A, filled circles) consisted of a mean of $95.1 \pm 1.3 \%$ correct responses on $0 \mathrm{sec}$ delay trials, decreasing to a mean of $69.0 \pm 2.5 \%$ correct responses on trials with interposed delays of $30 \mathrm{sec}$. After exposure to $\Delta^{9}$-THC, performance was not significantly altered $\left(F_{(1,231)}=1.44 ; p=0.23\right)$ at delays of $0-5$ sec but was significantly impaired at delays of $>5.0 \mathrm{sec}\left(F_{(1,231)}>7.21 ; p<0.01\right)$ and for all doses of $>0.5 \mathrm{mg} / \mathrm{kg}$. Increasing the dose of $\Delta^{9}$-THC altered the delay at which highly significant impairment occurred $(1.0 \mathrm{mg} / \mathrm{kg}$, $16-20 \mathrm{sec}, F_{(1,231)}=11.54 ; p<0.001 ; 1.5 \mathrm{mg} / \mathrm{kg}, 10-15 \mathrm{sec}, F_{(1,231)}$ $=12.61 ; p \stackrel{p}{<} 0.001 ; 2.0 \mathrm{mg} / \mathrm{kg}, 6-10 \mathrm{sec}, F_{(1,231)}=10.71 ; p<$ 


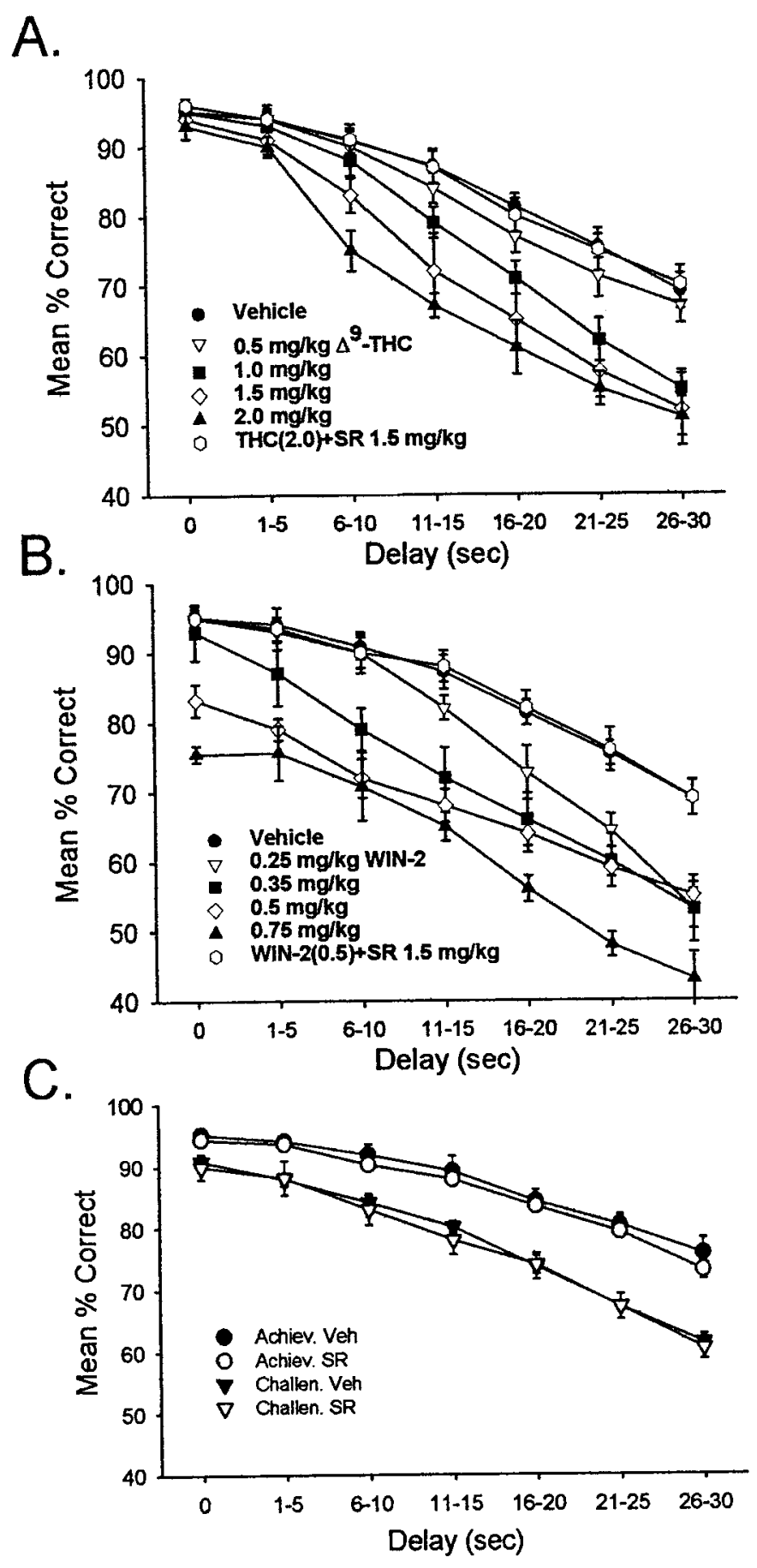

Figure 1. Cannabinoid effects on DNMS performance. $A$, DNMS performance curves after exposure to different doses of $\Delta^{9}$-THC. DNMS trials $(n=13$ animals) were sorted by length of delay, in increments of $5 \mathrm{sec}$, and are plotted as mean \pm SEM percent correct trials. Control (vehicle) performance is depicted by filled circles; performance after doses of $0.5,1.0$, 1.5 , and $2.0 \mathrm{mg} / \mathrm{kg} \Delta^{9}$-THC is depicted by triangles, squares, and diamonds, respectively. The effect of the CB1 receptor antagonist SR141716A (1.5 $\mathrm{mg} / \mathrm{kg}$ ) on the $2.0 \mathrm{mg} / \mathrm{kg}$ dose of $\Delta^{9}$-THC is indicated by the open circles. $B$, DNMS performance after exposure to the synthetic CB1 receptor agonist WIN-2. DNMS trials were sorted as in $A$ and plotted for effects of 0.25 , $0.35,0.5$, and $0.75 \mathrm{mg} / \mathrm{kg}$ doses of WIN-2. Open circles depict SR141716A $(1.5 \mathrm{mg} / \mathrm{kg})$ plus $0.5 \mathrm{mg} / \mathrm{kg} \mathrm{WIN}-2$. $C$, Effects of SR141716A $(1.5 \mathrm{mg} / \mathrm{kg})$ alone on DNMS performance curves ( $n=10$ animals). Shown are effects of exposure to $1.5 \mathrm{mg} / \mathrm{kg} \mathrm{SR} 141716 \mathrm{~A}$ in the absence of exogenously applied cannabinoids. Individual animals were divided into two groups based on the level of control DNMS performance: DNMS-achiever (Achiev.) animals $(n=4)$ performed on average 5-10\% better than did DNMS-challenged (Challen.) animals $(n=6)$. Filled symbols depict control (vehicle) DNMS performance; open symbols depict performance after SR141716A.
0.001). The effects of all doses of $\Delta^{9}$-THC were blocked by administration of the CB1 receptor antagonist SR141716A 10 min before $\Delta^{9}$-THC $\left(\mathrm{THC}+\mathrm{SR}\right.$, all delays, $\left.F_{(1,231)}=2.19 ; p=0.14\right)$. Thus, as previously reported, there was a dose $\times$ delay significant interaction $\left(F_{(20,231)}=3.15 ; p<0.001\right)$ in terms of the cannabinoid effects on DNMS performance.

Similar effects were obtained after exposure to the potent CB1 receptor agonist WIN-2, but the disruptive effects were produced at much lower doses. The lowest doses of WIN-2 (0.25 and 0.35 $\mathrm{mg} / \mathrm{kg})$ produced delay-dependent decreases in performance $(0.25$ $\mathrm{mg} / \mathrm{kg}, 16-20 \mathrm{sec}, F_{(1.231)}=14.63 ; p<0.001 ; 0.35 \mathrm{mg} / \mathrm{kg}, 6-10 \mathrm{sec}$, $\left.F_{(1,231)}=9.92 ; p<0.001\right)$ that were equivalent to those of $\Delta^{9}$-THC (Fig. 1 $A, B)$. However, at higher doses of WIN-2 (0.5 and 0.75 $\mathrm{mg} / \mathrm{kg})$ deficits at shorter delays were observed $(0.50 \mathrm{mg} / \mathrm{kg}, 0 \mathrm{sec}$, $F_{(1,231)}=15.92 ; p<0.001 ; 0.75 \mathrm{mg} / \mathrm{kg}, 0 \mathrm{sec}, F_{(1,231)}=27.31 ; p<$ $0.0001)$. As with $\Delta^{9}$-THC, all effects of WIN-2 were blocked by 10 min previous administration of SR141716A (WIN-2 + SR, $F_{(1,231)}$ $=1.47 ; p=0.23)$. In terms of mean percent correct performance within a session, WIN-2 at $0.35 \mathrm{mg} / \mathrm{kg}$ appeared to be equivalent to a $1.5 \mathrm{mg} / \mathrm{kg}$ dose of $\Delta^{9}$-THC. The deficit in DNMS performance on short-delay trials $(1-5 \mathrm{sec})$ produced by WIN-2 at high concentrations $(0.75 \mathrm{mg} / \mathrm{kg})$ has previously been shown to be reversed by the $\mathrm{GABA}_{\mathrm{B}}$ receptor antagonist phaclofen $(20 \mathrm{mg} / \mathrm{kg})$ coadministered with WIN-2 and likely involves added impairment of retrohippocampal areas (Hampson and Deadwyler, 1999, 2000).

The CB1 receptor antagonist SR141716A has been shown to effectively block the effects of exogenous cannabinoids as well as processes mediated by endogenous cannabinoids (Calignano et al., 1998; Mallet and Beninger, 1998; Akinshola et al., 1999), indicating that if endogenous cannabinoids are responsible for the delaydependent deficits in the DNMS task, performance might be facilitated by administration of the antagonist SR141617A alone (Rinaldi-Carmona et al., 1994). The effect of SR141716A alone on DNMS performance is shown in Figure $1 C$. For this test, animals were divided into "DNMS-challenged" $(n=4)$ and "DNMSachiever" $(n=6)$ groups on the basis of each animal's overall control (vehicle) session performance level. The achiever group performed significantly better over all delays than did the challenged group $\left(F_{(6,231)}=3.47 ; p<0.01\right)$. However, SR141716A at doses sufficient to block W IN-2 effects on DNMS performance (1.5 $\mathrm{mg} / \mathrm{kg}$ ) had no significant influence (see Fig. $1 C$ ) on either group of rats $\left(F_{(6,231)}<1.82 ; p>0.09\right.$ for all comparisons $)$ in terms of altering performance from that observed in control sessions.

\section{Effects of cannabinoids on hippocampal neural activity}

Figure 2 illustrates the summed activity of six hippocampal neurons recorded simultaneously from a single animal (CA1, $n=3$; CA3, $n=3$ ) summed across all $30 \mathrm{sec}$ delay trials for control (vehicle) and drug (WIN-2) DNMS sessions. The histograms depict the mean firing rate from $7.0 \mathrm{sec}$ before SR to $5.0 \mathrm{sec}$ after the occurrence of NR within the trial. The same neurons, as identified by wave shape and firing characteristics (Fig. 2, see waveform insets), were recorded on successive days after injection of WIN-2 $(0.35 \mathrm{mg} / \mathrm{kg}$; Fig. 2B, Cannabinoid) or vehicle (Fig. 2A, Vehicle). Under nondrug conditions the firing pattern of each neuron during the entire trial and selectively during task-relevant events (primarily SR, delay, and NR) was characterized with respect to significant increases in standard scores $(Z)$ of peak firing over a baseline level measured during the ITI. It is readily apparent that each of the six neurons exhibited different firing characteristics with respect to the other neurons in the ensemble (neurons $1-4$ and $6, Z>4.10 ; p<$ 0.001 for SR; neurons 1 and $3-5, Z>3.49$; $p<0.001$ for delay; neurons $2,3,5$, and $6, Z>5.10 ; p<0.001$ for NR), consistent with previous reports of identified hippocampal FCTs that encode specific features of the DNMS task (Hampson and Deadwyler, 1999b).

The predominant difference in hippocampal activity between Control (vehicle) and cannabinoid sessions was the marked attenuation of the firing during the sample phase (neurons 1, 3, 4, and 6, $Z<2.73$; $p>0.01$ ) and a significant decrease in "ramped" or progressively increasing firing across the delay interval (neurons 1, 
A.

B.
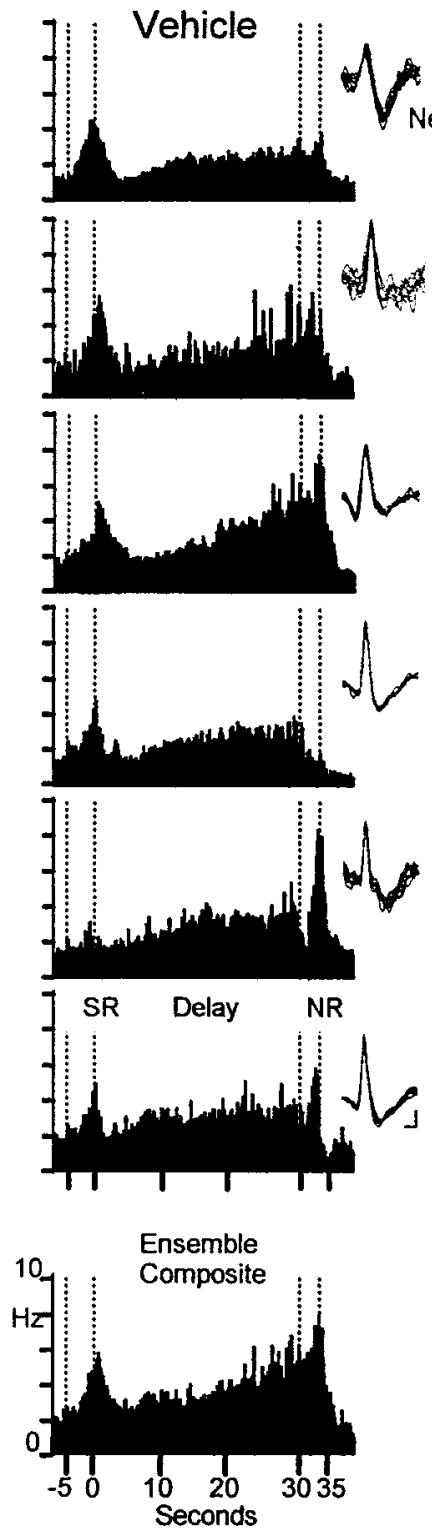
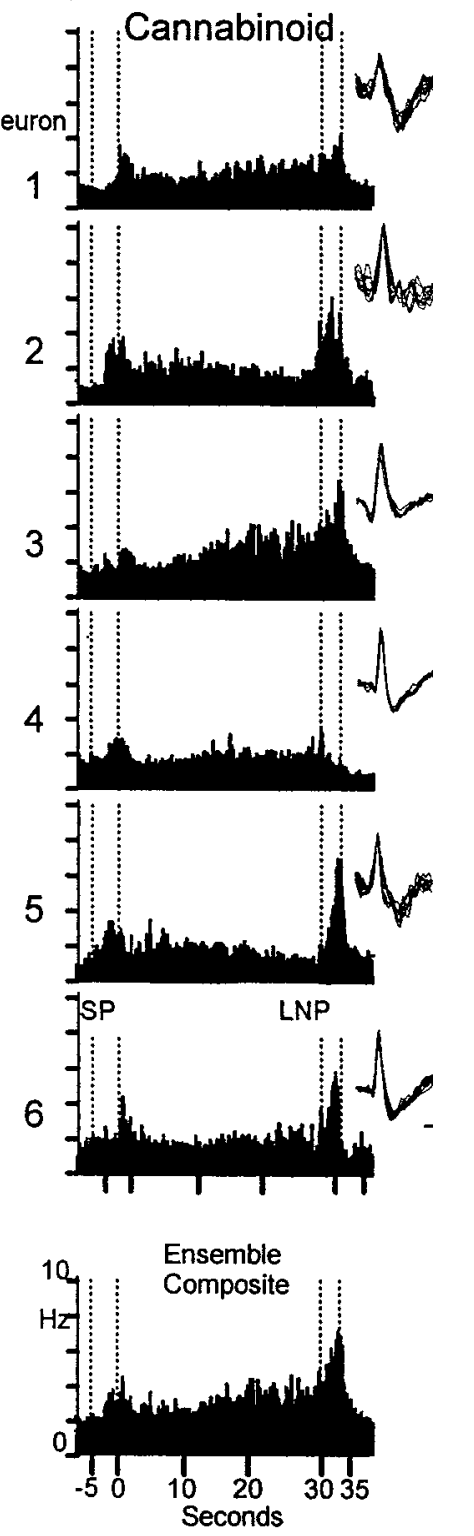

Figure 2. Simultaneously recorded hippocampal neuron firing during vehicle and cannabinoid sessions. Neurons $1-3$ were simultaneously recorded from CA3, and neurons 4-6 were recorded from CA1. Trial-based histograms (TBHs) depict averaged firing rates of each neuron on $30 \mathrm{sec}$ delay trials ( $n>75$ trials). the ensemble composite at the bottom reflects the average across all six neurons. $A$, TBHs representing firing in control session. $B$, TBHs recorded in W IN-2 $(0.35 \mathrm{mg} / \mathrm{kg})$ session. Waveform insets show the individual action potential waveforms used to discriminate these neurons during recording and indicate that the same neurons were recorded in both conditions. $S P$, Sample presentation; $S R$, sample response; $L N P$, last nose poke during the delay; $N R$, nonmatch response. Firing rate scale $(\mathrm{Hz})$ is shown on the ensemble composites. Calibration: $15 \mathrm{msec}, 25 \mu \mathrm{V}$.

2, 5, and 6, $Z<2.30 ; p>0.05$ ) shown in Figure $2 B$. The delay phase firing increase of all neurons (Fig. 2B, 2-6) was either markedly attenuated or eliminated during cannabinoid sessions. However, neuron 5, an FCT in which increased firing in the Sample (SR) was not a correlate, shows that firing in the NR period was unaffected by cannabinoid exposure (Fig. $2 A, B$ ). Overall, of the neurons recorded within each ensemble, the mean SR peak firing was reduced by $35 \%$ (control, $2.91 \pm 0.31 \mathrm{~Hz}$; cannabinoid, $1.82 \pm$ $\left.0.34 ; F_{(1,239)}=7.22 ; p<0.01\right)$ in amplitude, whereas overall, firing across the delay interval was reduced by $40 \%$ (control, $2.60 \pm 0.34$ $\mathrm{Hz}$; cannabinoid, $\left.1.45 \pm 0.27 \mathrm{~Hz} ; F_{(1,239)}=9.10 ; p<0.001\right)$. In contrast, NR firing was reduced by no more than $10 \%$ (control,

$3.63 \pm 0.35 \mathrm{~Hz}$; cannabinoid, $3.32 \pm 0.45 \mathrm{~Hz}$ ), which was not significant $\left(F_{(1,239)}=2.31 ; p=0.13\right)$.

A comparison of the effects of behaviorally equivalent doses of $\Delta^{9}$-THC $(1.5 \mathrm{mg} / \mathrm{kg})$ versus WIN-2 $(0.35 \mathrm{mg} / \mathrm{kg})$, as depicted in Figure 1, $A$ and $B$, on hippocampal neural firing is shown in Figure $3 A$, top. Relative to control (vehicle) session firing, both $\Delta^{9}$-THC and WIN-2 caused similar attenuations in sample and delay phase firing $\left(F_{(1,239)}>8.3 ; p<0.005\right.$, all comparisons), with little effect on firing during the nonmatch phase of the task (all $F_{(1,239)}<2.7$; $p>0.11$ ), albeit at different dose levels. Specific comparisons of $\Delta{ }^{9}$-THC $(1.5 \mathrm{mg} / \mathrm{kg})$ and WIN-2 $(0.35 \mathrm{mg} / \mathrm{kg})$ effects on firing showed no significant difference in firing during the sample $\left(F_{(1,239)}\right.$ $=1.8 ; p=0.19)$, delay $\left(F_{(1,239)}=2.1 ; p=0.15\right)$ and nonmatch $\left(F_{(1,239)}=2.7 ; p=0.11\right)$ phases. The cannabinoid reduction in SR peak and delay firing was blocked in the case of both drugs by co-administration of the CB1 receptor antagonist SR141716A (all $\left.F_{(1,239)}<1.5 ; p>0.22\right)$; however, as was the case with DNMS behavior, administration of the antagonist alone did not significantly alter ensemble firing compared with control sessions (all $F_{(1,239)}<1.2 ; p>0.27$; Fig. $\left.3 A\right)$. Figure 3 shows cannabinoid dose effects on hippocampal neural activity. Consistent with the behavioral effects of WIN-2, the degree of suppression of hippocampal neuron firing in the DNMS task varied over the same narrow dose range of $0.25-0.50 \mathrm{mg} / \mathrm{kg}$ (Fig. $3 B ; n=85$ cells, 8 animals; $F_{(3,239)}$ $=5.6 ; p<0.001)$. There were significant dose-dependent decreases in ensemble firing in both the sample and delay phases of the task but not in the nonmatch phase, except at the highest dose $(0.50$ $\mathrm{mg} / \mathrm{kg}$ ) (Fig. 3A).

A major correlate of normal DNMS performance demonstrated in the past is the reduction or absence of SR and delay firing on error trials. Figure $4 A$ shows that the reduced SR firing associated with error trials also occurs in cannabinoid sessions. Separate composite ensemble histograms (i.e., firing rates of all neurons in the ensemble averaged over the trial) were constructed from correct versus error trials of the same duration $(n=500$ trials $)$ for control and cannabinoid (WIN-2, $0.35 \mathrm{mg} / \mathrm{kg}$ ) sessions for a single animal. The mean firing rate at the SR peak for correct trials in control sessions was $3.89 \pm 0.21 \mathrm{~Hz}$, whereas the mean rate for correct trials in cannabinoid sessions was $2.94 \pm 0.17 \mathrm{~Hz}\left(F_{(1,239)}=\right.$ 9.45; $p<0.01)$. Firing across the delay interval of correct trials was similarly reduced by cannabinoids (control, $3.57 \pm 0.32 \mathrm{~Hz}$; cannabinoid, $\left.2.06 \pm 0.25 \mathrm{~Hz} ; F_{(1,239)}=9.13 ; p<0.001\right)$. On error trials, SR firing was also significantly decreased after exposure to cannabinoids (control, $2.67 \pm 0.11 \mathrm{~Hz}$; cannabinoid, $1.87 \pm 0.17$ $\left.\mathrm{Hz} ; F_{(1,239)}=7.87 ; p<0.01\right)$. However, it is important that the background firing during the ITI was not significantly changed from control levels during cannabinoid sessions (control, $=1.09 \pm$ $0.29 \mathrm{~Hz}$; cannabinoid, $\left.1.27 \pm 0.19 \mathrm{~Hz} ; F_{(1,239)}=1.29 ; p=0.27\right)$. Thus, the reduction in SR peak on both correct and error trials was not caused by an overall decrease in background firing level.

This is further illustrated by sorting overall ensemble firing rates by correct versus error performance as a function of delay interval. The bar graphs in Figure $4 B$ depict mean peak SR firing rates for ensembles sorted according to the length of delay interval on the same trial and as a function of performance. For control sessions the black bar indicates mean ensemble SR firing rate for all trials, which did not differ significantly with respect to delay interval (mean, $\left.4.31 \pm 0.42 \mathrm{~Hz} ; F_{(1,463)}=1.08 ; p=0.29\right)$. However, an analysis of error trial SR firing rates indicated that the lowest rate for correct trials (white bars) increased from $1.79 \mathrm{~Hz}$ for trials with delay intervals of $\leq 10 \mathrm{sec}$ to $2.11 \mathrm{~Hz}$ for trials with $\leq 20 \mathrm{sec}$ delays and $2.81 \mathrm{~Hz}$ for $\leq 30 \mathrm{sec}$ trials. Thus the minimum firing rate associated with a correct trial increased by $57 \%$ as the delay interval lengthened from 10 to $30 \mathrm{sec}$. These levels are illustrated as horizontal lines on the composite histograms in Figure $4 \mathrm{~A}$, left, which reflects the likelihood of increased errors at longer delay intervals (Fig. 1). The mean firing rate across all trials was reduced in cannabinoid (WIN-2, $0.35 \mathrm{mg} / \mathrm{kg}$ ) sessions $(3.01 \pm 0.41 \mathrm{~Hz})$ compared with control firing $\left(F_{(1,463)}>8.21 ; p<0.01\right)$. The minimum firing rate associated with correct trials was not signifi- 
A.
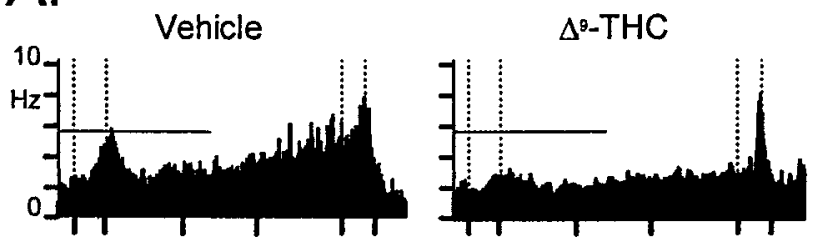

SR141716A

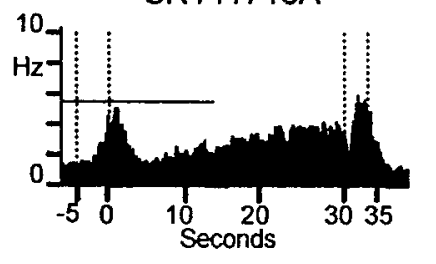

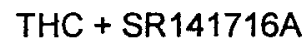

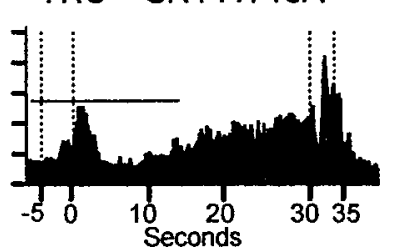

WIN-2

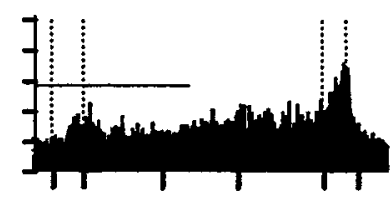

WIN-2 + SR141716A

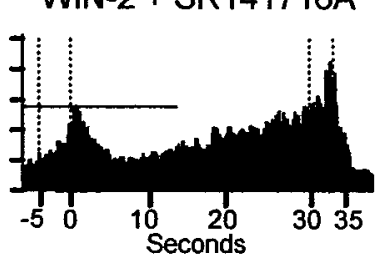

B.

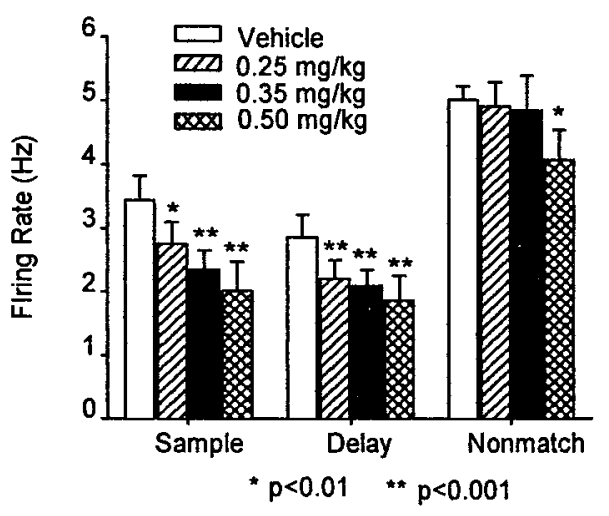

Figure 3. Effects of type and concentration of cannabinoid on hippocampal neural firing. $A$, Composite TBHs for simultaneously recorded neurons as in Figure 2, during $\Delta^{9}$-THC, WIN-2, and SR141716A sessions. TBHs show similar influences of $1.5 \mathrm{mg} / \mathrm{kg} \Delta^{9}$-THC and $0.35 \mathrm{mg} / \mathrm{kg}$ WIN-2 on neural ensemble activity in agreement with behavioral effects. Co-administration of SR141716A blocked effects of $\Delta^{9}$-THC and WIN-2 but produced no effects on firing when administered alone (bottom left). B. Concentration dependence of WIN-2 effects on hippocampal neural firing. Bar graphs depict mean of SR firing peak, last $5 \mathrm{sec}$ during delay phase, and NR peak ( $n=85$ neurons in 7 animals). Each animal was exposed to three concentrations of WIN-2: $0.25,0.35$, and $0.50 \mathrm{mg} / \mathrm{kg}$ in a balanced design with at least two control (vehicle) daily sessions interposed between drug sessions. Mean firing rate for each phase was averaged across ensembles and is plotted according to WIN-2 dose. Asterisks indicate significant reduction in firing rate from control sessions (*all $F_{(1,252)}>6.9 ; p<0.01 ; * *$ all $\left.F_{(1,252)}>11.2 ; p<0.001\right)$.

cantly different for cannabinoid sessions $(10 \mathrm{sec}, 1.71 \mathrm{~Hz} ; 20 \mathrm{sec}$, $2.15 \mathrm{~Hz} ; 30 \mathrm{sec}, 2.69 \mathrm{~Hz}$; all $\left.F_{(1,463)}<0.79 ; p>0.37\right)$ compared with control (see above). The margin of difference between successful encoding and errors for a given delay was significantly decreased (difference from overall mean, $F_{(1,463)}>9.5 ; p<0.01$ ) in cannabinoid sessions. It is important to emphasize that this measure does not simply reflect an increase in firing of all cells in the ensemble but only those cells that make up the particular pattern of firing associated with specific task-relevant events within a particular trial (Deadwyler et al., 1996).

\section{Cannabinoid effects on ensemble representation of DNMS task information}

A CDA was performed separately on ensemble data recorded from each animal in both control (vehicle) and drug sessions (Deadwyler et al., 1996; Hampson and Deadwyler, 1998a). The discriminant scores were then analyzed for differences in firing with respect to cannabinoid versus control sessions using multivariate ANOVAs (Stevens, 1992). The analysis yielded a set of discriminant functions (DFs) from each ensemble, which partitioned the variance contributions correlated with each task-relevant event. Of the five significant DFs $\left(F_{(1,5717)}>7.48 ; p<0.01\right.$, for all significant DFs) obtained from each of the nine recorded ensembles (animals), three were directly related to information that was required to perform the task and accounted for the majority of ensemble firing variance $(61 \%)$ : task phase (sample or nonmatch DF1), which accounted for $42 \%$ of total variance; response position (DF4, 11\% of variance); and trial type (DF5, 8\% of variance). For each DF, only Sample phase firing variance was altered by cannabinoids. The mean score for DF1 (task phase) during the Sample was reduced from $-2.64 \pm 0.57$ for control sessions to $-1.43 \pm 0.89$ in sessions preceded by WIN-2 injections $\left(F_{(1,5717)}=9.92 ; p<0.001\right)$, whereas ensemble firing in the nonmatch phase (mean DF1 control, $+2.98 \pm 0.77 ;$ WIN-2, +2.64 \pm 0.82 ) was unchanged from control $\left(F_{(1,5717)}=1.72 ; p=0.19\right)$. Likewise, in W IN-2 sessions, the Sample phase scores for DF4 (response position) were significantly reduced from control (control left sample, $+1.09 \pm 0.52$; control right sample, $-1.18 \pm 0.68$; WIN-2 left sample, $+0.43 \pm$ 0.51 ; W IN-2 right sample, $\left.0.35 \pm 0.53 ; F_{(1,5717)}=11.2 ; p<0.001\right)$, whereas Nonmatch phase position scores were not affected. Finally, scores for DF5 also showed a significant WIN-2-induced reduction during the Sample phase (control right sample, $+1.03 \pm 0.36$; control left sample, $-1.41 \pm 0.52$; W IN-2 right sample, $+0.32 \pm$
0.57 ; WIN-2 left sample, $\left.-0.51 \pm 0.49 ; F_{(1,5717)}=9.74 ; p<0.001\right)$ with no change in the scores during the Nonmatch phase. These analyses confirmed that a significant effect of cannabinoids was to reduce ensemble firing during the sample phase while leaving nonmatch phase firing untouched.

\section{Effects of cannabinoids on sample encoding strength}

The loss of sample firing produced by exposure to cannabinoids shown in Figures 2-4 correlates with reduced performance and suggests insufficient encoding of sample information. Such "weak" encoding in this task has been previously linked to increased errors, especially when long-delay trials are encountered (Hampson and Deadwyler, 1996). The determination of the strength of encoding of the sample response was indicated by the ensemble firing rate and was used to assess the change in probability of behavioral errors produced by cannabinoids. Ensemble firing rates at the SR on each trial are shown as a frequency distribution of firing rates on individual trials in control and cannabinoid sessions for a single animal in Figure 5. Exposure to WIN-2 resulted in a shift in the distribution toward weaker encoding in the form of more trials with lower ensemble firing rates during the SR. Comparison with the control distribution indicates that during WIN-2 sessions a greater number of trials were "at risk" (gray bars) for errors in that they were below the necessary firing rate for being correct on any trial (Fig. 5A). Correspondingly, median Sample firing was $31 \%$ lower during cannabinoid sessions (control, $3.18 \mathrm{~Hz}$; WIN-2, $2.21 \mathrm{~Hz}$; $\left.t_{(20)}=5.24 ; p<0.001\right)$.

Given the relationship of ensemble firing frequency in the sample phase of the trial to DNMS performance, it was possible to derive the following "encoding function" relating strength (frequency) of encoding to the likelihood of a correct response:

$$
\text { probability of correct trial }=1 /\left(1+e^{(-(x-\beta 2) / \beta 1)}\right),
$$

where $x$ is SR firing rate on that trial, and $\beta 1$ and $\beta 2$ are coefficients of firing and slope, respectively, in which $\beta 1$ incorporates the minimum firing rate to produce a correct response for a trial at a given duration of delay (Fig. $5 B$ ), and $\beta 2$ represents the change in firing rate required to increase performance. This encoding function is graphed in Figure $5 B$, which shows the probability of a correct response (mean $\pm \mathrm{SEM}$ ) for each level of ensemble firing rate. Interestingly, the values of the coefficients of the encoding function were the same for both control and WIN-2 sessions $(\beta 1=$ 

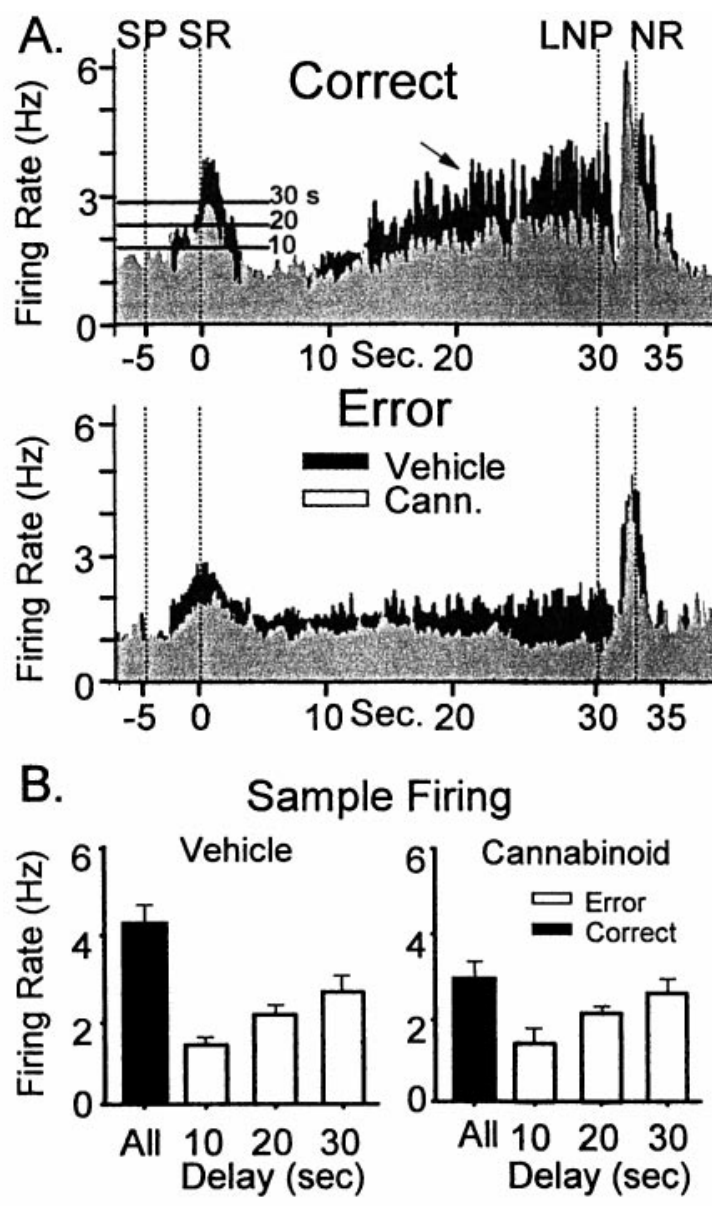

Figure 4. Effects of cannabinoids on correct and error DNMS trials. $A$, Black TBHs depict ensemble composite firing in control sessions; light gray TBHs depict ensemble firing in WIN-2 $(0.35 \mathrm{mg} / \mathrm{kg})$ sessions. Firing on correct DNMS trials is shown above (Correct); firing on error trials is shown below (Error). The arrow indicates the typical ramped increase in firing during the delay phase on correct trials that is absent on error trials. $S P$, Sample presentation; $S R$, Sample response; $L N P$, last nosepoke; $N R$, Nonmatch response. Horizontal lines on histograms at SR indicate minimum peak firing rate for correct performance at the indicated delay. $B$, Strength of SR encoding depicted by ensemble firing. Bar graphs depict mean SR peak firing rates over all correct trials (black bars) compared with the maximum firing rate seen on error trials (white bars) for vehicle (left) and cannabinoid (WIN-2 $0.35 \mathrm{mg} / \mathrm{kg}$, right) sessions. Trials were sorted according to length of delay $(0-10,11-20$, and $21-30 \mathrm{sec})$. White bars reflect the maximum firing rate that resulted in an error for those delay categories. The distribution of maximum firing rates for error trials was not significantly different, although the overall mean firing rate for all correct trials was significantly reduced in cannabinoid sessions.

$0.45 ; \beta 2=0.95)$, showing that although firing rates in the sample phase were reduced in WIN-2 sessions, the same encoding function predicted the likelihood of a correct trial. The firing rate distributions shown in Figure $5 A$ and the encoding function in Figure $5 B$ were used to generate the cumulative performance curves for control and WIN-2 sessions shown in Figure $5 C$. It is clear that the curve for WIN-2 asymptotes at a lower overall percentage $(60 \%)$ of correct trials than for control sessions, which reflects an increased number of trials with lower encoding strength (Fig. 5A). This analysis shows that cannabinoids reduced performance levels relative to the control sessions as a direct result of the reduction in encoding strength during the SR.

\section{Cannabinoids reduce ensemble information content}

Previous studies of hippocampal ensemble activity demonstrated that the various patterns of neuronal firing within the ensemble encoded task-relevant information (Hampson and Deadwyler, 1996; Hampson et al., 1998b). Successful encoding of task-relevant features is measured by the information content $\left(I_{\text {ens }}\right)$ of the ensemble activity:

$$
I_{\mathrm{ens}}=\sum_{j=1}^{n} \sum_{k=1}^{n} p\left(a_{\mathrm{j}}, b_{\mathrm{k}}\right) \times \log \left[p\left(a_{\mathrm{j}}, b_{\mathrm{k}}\right) \div\left(p\left(a_{\mathrm{j}}\right) \times p\left(b_{\mathrm{k}}\right)\right)\right]
$$

where $p\left(a_{\mathrm{j}}\right)$ is the probability that one of the $n$ task-relevant events (e.g., right sample) has occurred, $p\left(b_{\mathrm{k}}\right)$ is the probability that the CDA classified the ensemble firing as that particular event, and $p\left(a_{\mathrm{j}}, b_{\mathrm{k}}\right)$ is the joint probability of a particular event occurring and being correctly classified by the CDA. This yields an ensemble $I_{\text {ens, }}$ the instantaneous summed information content for all neurons in the ensemble when recorded simultaneously (Hamming, 1986; Gochin et al., 1994; Hampson and Deadwyler, 1998b). The analysis uses the CDA DF scores to classify trials and quantifies all possibilities of correct and incorrect classifications of each behavioral event (Stevens, 1992). Analyses showed that of the three "bits" of information in the DNMS task [trial phase, lever position, and performance outcome (correct or error)], a mean of 2.75 bits (Fig. $5 D$, Control) were encoded across all ensembles $(n=14)$ of 10 simultaneously recorded hippocampal neurons as shown in Figure $5 D$, Control. In contrast, the same neurons analyzed as if recorded serially, one at a time, or "shuffled" across different ensembles (animals) showed a significant $\left(F_{(1,158)}=23.5 ; p<0.001\right)$ reduction to only 1.27 bits encoded (Fig. $5 D$, Serial). The increase in ensemble information content over neurons recorded separately (serial) reflects the degree to which coherence via consistent covariances between neurons can be detected by the CDA during task relevant events. From this analysis, it could be estimated that 18-20 neurons were required to correctly encode the entire three bits of information in the control condition (Fig. 5E). For serial recorded neurons the estimated number of neurons required to encode the same amount of information jumps to $>100$ (Fig. 5E, Serial).

In cannabinoid sessions (WIN-2, $0.35 \mathrm{mg} / \mathrm{kg}$ ) the $I_{\text {ens }}$ for hippocampal ensembles was also significantly reduced $\left(F_{(1,158)}=11.4\right.$; $p<0.001)$ but to a lesser degree than in shuffled control conditions. The information content was 1.81 information bits per trial (Fig. $5 D$, Cannab.), a $33 \%$ decrease from control (vehicle) sessions. The estimated number of neurons required to encode the 3 bits of information in WIN-2 sessions was increased significantly from control to $>50$ but remained below that estimated for serial recording conditions (Fig. 5E, Cann.). This reduction in information content and increase in number of neurons required to encode the same information as in control sessions reflects an exclusive influence of cannabinoids on hippocampal mechanisms of information processing and confirms their selective memory disruptive nature reflected in the delay-dependent deficit in DNMS performance (Fig. 1).

\section{Cannabinoids produce selective changes in functional hippocampal cell types}

Extending the investigation of cannabinoid-induced changes in ensemble firing characteristics further, an assessment of changes in individual neuron firing patterns within the ensemble was conducted. The approach relied on the CDA DFs, described above to identify and classify different types of individual neuron firing patterns that made up the overall ensemble "code" for a particular task-relevant event. In a recent report (Hampson et al., 1999b) a classification scheme for hippocampal neurons into FCTs within the DNMS task was described. The firing patterns of 67 individual neurons distributed within each ensemble $(n=6)$ were examined for firing components that correlated with behavioral events. It was possible to identify four different FCTs that fired with unique characteristics: phase cells, which fired differentially during the sample or nonmatch phase irrespective of trial type; position cells, which fired only during responses on the left or right lever irrespective of the phase of the task; conjunctive cells, which fired only when a particular combination of position and phase occurred (e.g., left nonmatch or right sample) and did not fire in response to any 

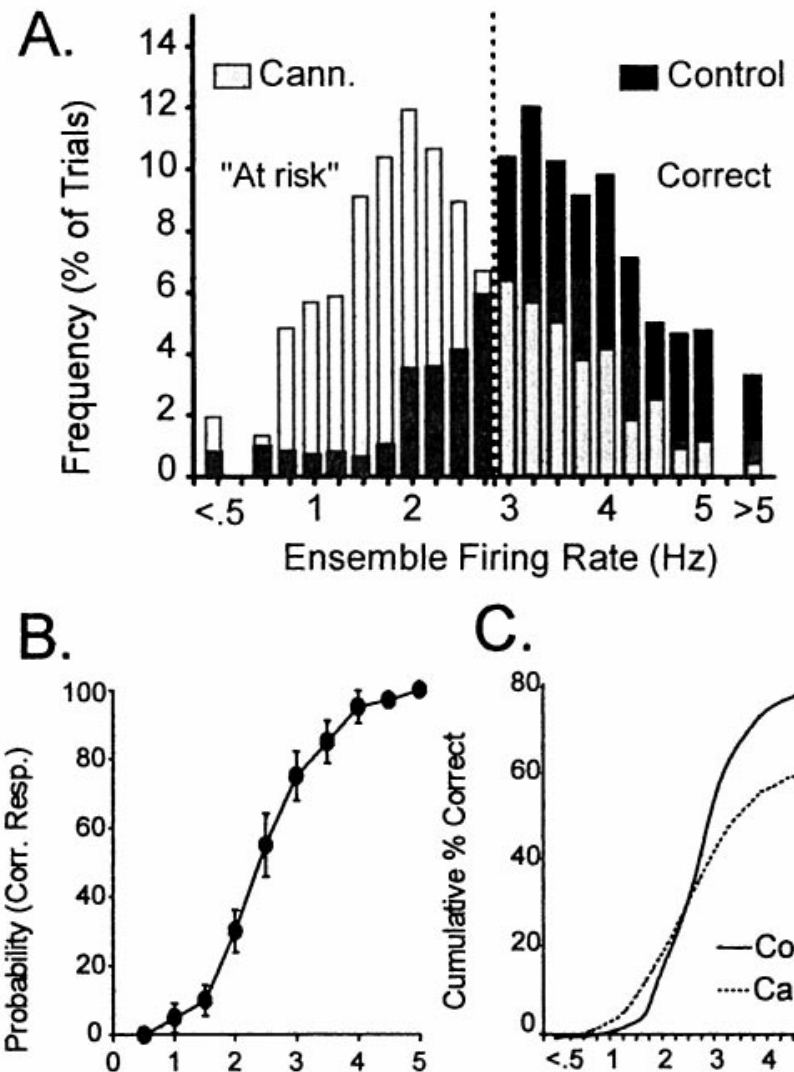

Ensemble Firing Rate $(\mathrm{Hz})$
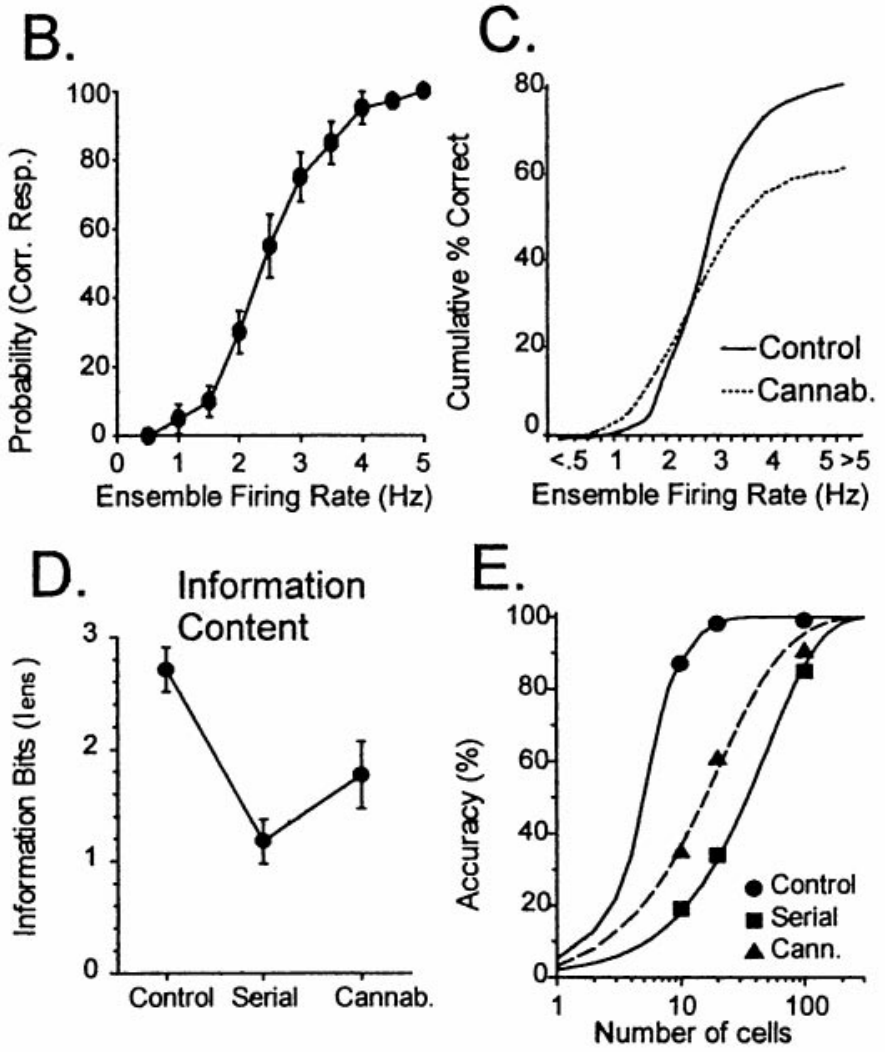

Figure 5. Cannabinoid effects on Sample encoding strengths derived from ensemble mean SR firing rate. A, Bar graph depicts frequency distribution of SR encoding over a 100-trial session for a single animal. Black bars indicate distribution of encoding on control (vehicle) trials; gray bars indicate distribution of SR firing frequencies after exposure to cannabinoid (WIN-2, $0.35 \mathrm{mg} / \mathrm{kg}$ ). Bars to the right of the dashed vertical line indicate trials that would be correct at any delay; bars to the left indicate trials that may result in errors at $30 \mathrm{sec}$ delays and hence are at risk for errors. $B$, Encoding function (see text) derived from relationship between encoding strength (SR firing rate) and probability of correct trial. Symbols indicate mean \pm SEM probability of correct response for trials with a given ensemble firing rate. The curve of the encoding function was fitted to the data points as described in text. $C$, Behavioral outcome derived by using encoding function in $B$ and SR firing rate distributions in $A$. The frequency of trials at each increment of firing rate was multiplied by the probability of a correct response and divided by total trials to yield the cumulative measure of correct performance within the session. Separation of control and cannabinoid curves denotes increased errors resulting from reduced SR encoding. $D$, Reduced SR encoding capacity of hippocampal neural ensembles is reflected by $I_{\text {ens }}$ for simultaneously recorded ensembles of 10-15 neurons $(n=7)$ animals under control conditions (Control) and after randomization of data consistent with serial recording of individual neurons (Serial). $I_{\text {en }}$ was also computed for simultaneously recorded ensembles after exposure to WIN-2 $(0.35 \mathrm{mg} / \mathrm{kg}$; Cannab.). Cannabinoids reduced the information content of the ensemble from control levels but not to the same degree as serial reconstruction of the data. $E$, Accuracy of ensembles of varying sizes
Table 1. Cannabinoid effects on hippocampal FCTs

\begin{tabular}{lll} 
& No. of cells & \\
\cline { 2 - 3 } FCT & Vehicle & Cannabinoid \\
\hline Sample phase only & 11 & 3 \\
Nonmatch phase only & 11 & 9 \\
Left position only & 6 & 1 \\
$\quad$ Altered & & 5 \\
Right position only & 7 & 2 \\
$\quad$ Altered & 7 & 5 \\
Left sample & 6 & 2 \\
Right sample & 8 & 1 \\
Left nonmatch & 11 & 7 \\
Right nonmatch & & 10
\end{tabular}

Altered cells exhibited decreased firing in the Sample but not the Nonmatch phase of the task (see Results).

of the other possible combinations (e.g., right nonmatch, right sample, or left sample); and trial-type cells, which increased firing during all task-relevant trials but for only one of the two types of trial (i.e., right sample-left nonmatch or left sample-right nonmatch). The FCTs $(n=67)$ recorded in six different animals are summarized in Table 1.

FCTs were characterized in sessions in which WIN-2 $(0.35$ $\mathrm{mg} / \mathrm{kg}$ ) was administered. Figure 6 , Vehicle, left, shows examples of firing patterns of three different FCTs, a left position cell, a left nonmatch conjunctive cell, and a right sample conjunctive cell in terms of raster plots and histograms constructed $1.5 \mathrm{sec}$ around the respective task-relevant events that they encode. Figure 6, right, shows the same types of display from the same cell recorded during a WIN-2 (Cannabinoid) session. It is clear that in the WIN-2 session neither the left position nor right sample conjunctive cells maintained increased firing rate in the Sample phase of the task (Fig. 6, compare left columns). In contrast, the left position and left Nonmatch conjunctive cell firing patterns were unchanged in the nonmatch phase during WIN-2 sessions (Fig. 6, right columns). The results for all cells are summarized in Table 1 and show that of the 37 cells that normally increased firing in the sample phase (i.e., left or right position only, sample-only, left or right trial type, and left and right sample FCTs), only 9 retained that functional correlate during WIN-2 sessions. In contrast, 29 of 43 neurons with nonmatch firing correlates (i.e., left or right position only, nonmatchonly, left or right trial type, and left or right nonmatch FCTs) showed no significant change in firing during WIN-2 sessions. All affected FCTs resumed their respective firing correlates when recorded $22 \mathrm{hr}$ later in control (vehicle) sessions. Figure 6 also illustrates the fact that firing could be differentiated by cannabinoids with respect to a single FCT as indicated by the selective effect on the left position cell on Sample but not Nonmatch phase firing during WIN-2 sessions (Fig. 6, top right).

The distribution of the above FCTs within the hippocampus was also of interest, because a recent report from this laboratory showed neurons categorically organized in 200-300 $\mu \mathrm{m}$ segments along the longitudinal expanse of the hippocampus (Hampson et al., 1999b). Figure 7, top, shows the relative anatomic location of the 67 neurons in Table 1 plotted on a fold-out map spanning 2.0 $\mathrm{mm}$ of dorsal hippocampus. The FCTs recorded during control sessions fit the anatomic organizational scheme described previously with phase cells interleaved with position cells and conjunc-

$\leftarrow$

to encode 3 bits of information in the DNMS task computed using $I_{\mathrm{ens}}$ from $D$. Power function curves show that ensembles of 10-20 simultaneously recorded neurons provide $>90 \%$ accuracy in encoding all relevant DNMS events. Serially reconstructed ensembles would require $>100$ neurons to reach the same accuracy. After exposure to cannabinoids, the accuracy of the same $10-20$ neuron ensembles dropped to $30-60 \%$, requiring nearly 100 neurons to reach the same accuracy as control. 

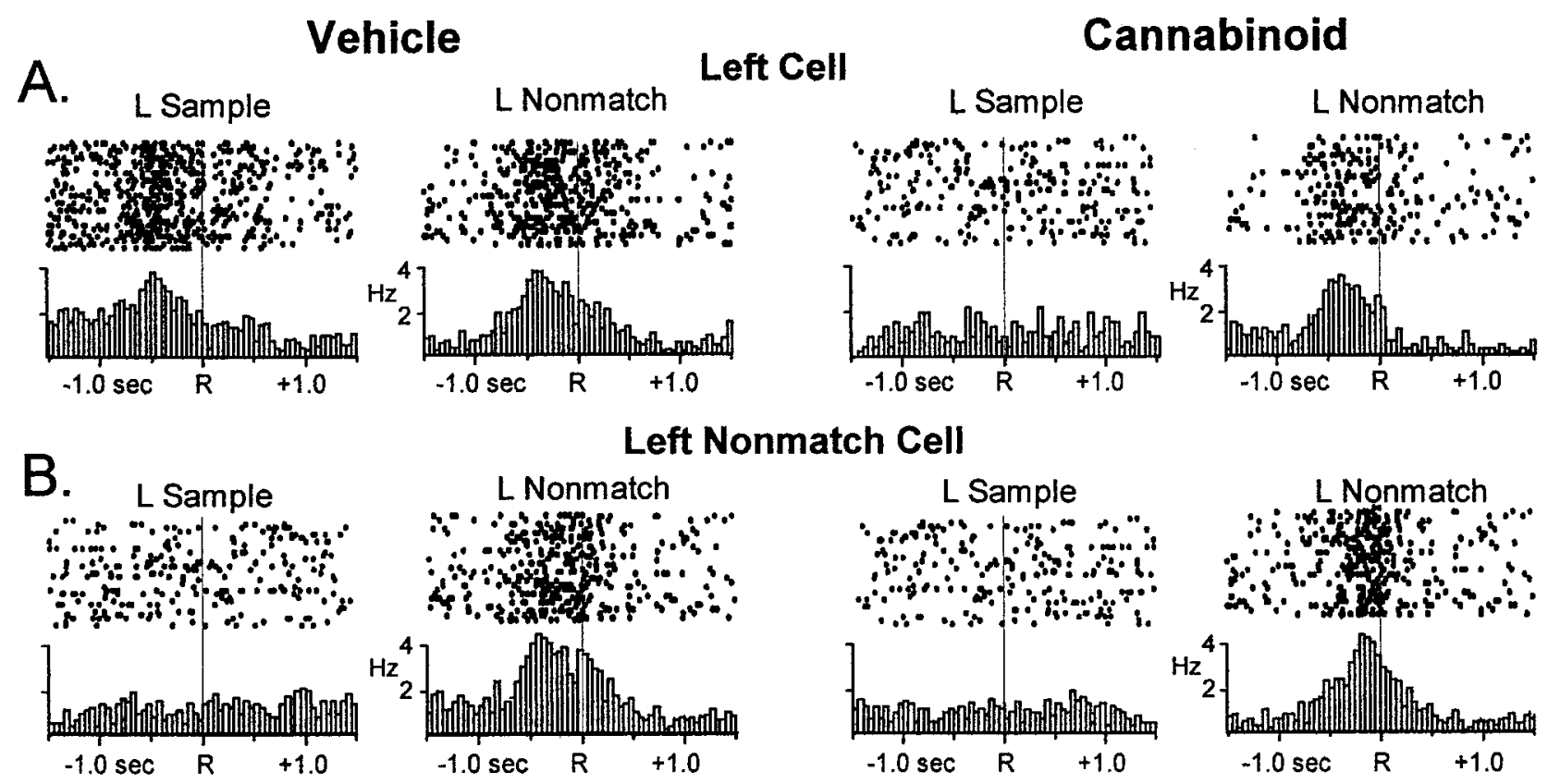

Left Nonmatch Cell
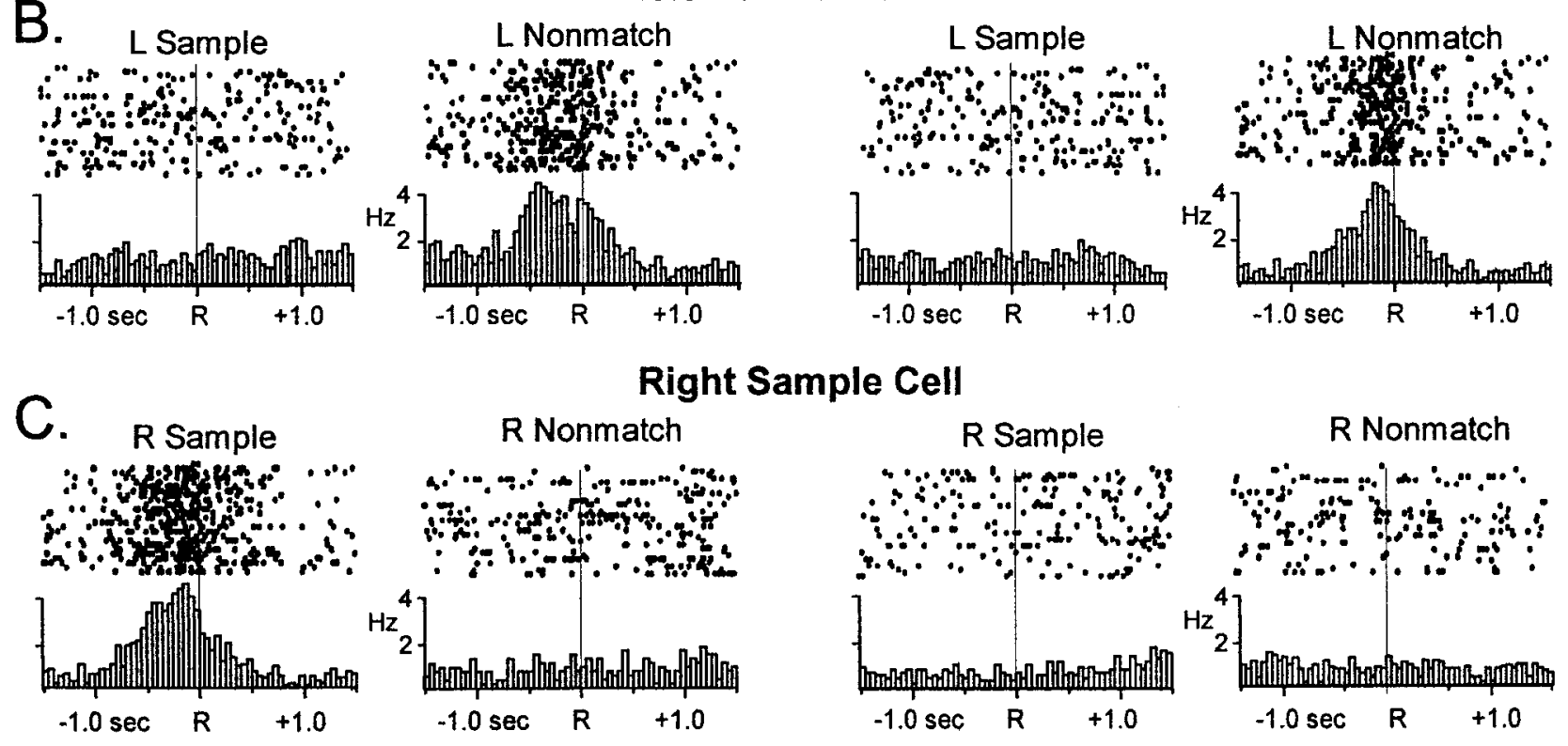

\section{Right Sample Cell}
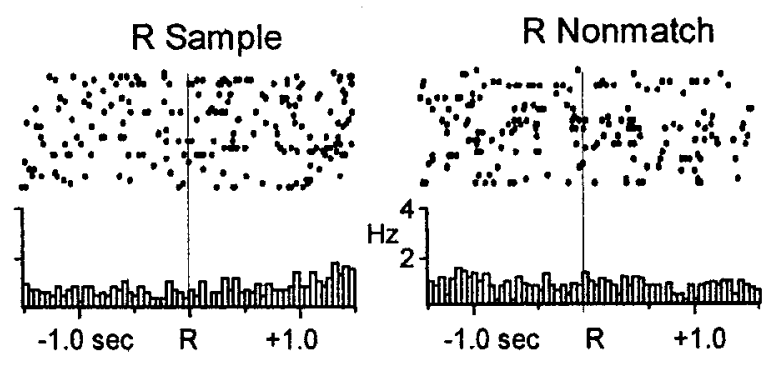

Figure 6. Raster and perievent histograms (PEHs) of three hippocampal FCTs simultaneously recorded in the DNMS task. Rastergrams illustrate firing on single trials with a dot each time the cell fired an action potential in relation to the sample or nonmatch response. Successive rows depict 20 different trials. PEHs below illustrate summed firing across 100 trials for the same $\pm 1.5 \mathrm{sec}$ interval. $A$, A left position cell fires in the sample and nonmatch phases at the left lever response (left panel, Vehicle). The right panel shows loss of sample phase firing but retained Nonmatch phase firing after exposure to cannabinoid (WIN-2, $0.35 \mathrm{mg} / \mathrm{kg}$ ). B, A left nonmatch conjunctive cell (left panel) fires only during the left nonmatch phase but not the left sample phase. Left nonmatch firing was unaffected by cannabinoid exposure (right panel). $C$, A right sample conjunctive cell fired only during the sample phase at the right lever response (left panel). Specific firing of this cell was eliminated after exposure to cannabinoid.

tive cells distributed appropriately within that rubric. W IN-2 (0.35 $\mathrm{mg} / \mathrm{kg}$ ) did not change the locations of identified FCTs in the control sessions; it did, however, alter (Table 1) or suppress the firing of FCTs located at specific locations. A major indicator of this tendency was the position cells in which firing in the Sample phase was suppressed (also see Table 1), but firing remained during the nonmatch phase of the trial, which could be verified by the fact that they were located in the same anatomic location (Fig. $7, *, \times$ ). Since drug and nondrug sessions were alternated, the suppression of FCT firing at specific locations during the Sample phase was shown to be completely reversible, and normal FCT firing could be observed both before and after WIN-2 or $\Delta^{9}$-THC sessions.

\section{DISCUSSION}

The results of the current study support and extend our previous findings with respect to cannabinoid effects on short-term memory deficits in the rat (Heyser et al., 1993; Hampson and Deadwyler, 1998a, 1999) and are consistent with other reports using different behavioral paradigms (Lichtman et al., 1995; Lichtman and Martin, 1996; Ferrari et al., 1999; Reibaud et al., 1999). This study provides additional comparative dose-effect data of the potent CB1 receptor ligand WIN-2 in relation to $\Delta^{9}$-THC in a different short-term memory (DNMS) task than previously (DMTS; Heyser et al., 1993). The behavioral effects of cannabinoids presented here can now be directly compared with those produced by selective hip- pocampal removal in the DNMS task (Hampson et al., 1999a); however, unlike lesion studies, the effects of cannabinoids were completely reversed within $24 \mathrm{hr}$ of drug exposure.

The fact that cannabinoids and hippocampal removal produced similar deficits suggests that cannabinoids have selective actions on information processing within the hippocampus. The pharmacological basis of this assumption was confirmed by (1) the replication of the dose $x$ delay interaction of the magnitude of short-term memory deficits demonstrated for both $\Delta^{9}$-THC and WIN-2, with the latter showing an increased potency over a narrower dose range (Fig. 1); and (2) the effective blockade of CB1 receptor ligands with the antagonist SR141617A (Fig. 1). It has been suggested that selective reduction in endogenous cannabinoids might be beneficial in short-term memory as well as other learning contexts (Brodkin and Moerschbaecher 1997); however, the lack of an enhancing effect on DNMS performance in the current study with the antagonist SR141617A alone (Terranova et al., 1996; Nakamura-Palacios et al., 2000) indicates that the role of endogenous cannabinoid substances in normal DNMS behavior is not as yet well understood (Fig. 1C).

Also, as previously demonstrated with $\Delta^{9}$-THC, the more potent agonist WIN-2 selectively depressed cell firing in the sample phase of the task in a dose-dependent manner, which was consistent with its behavioral effects at those same doses (WIN-2; Fig. 3). The cannabinoid-induced suppression of overall Sample phase firing 


\section{Control}

\section{Cann.}
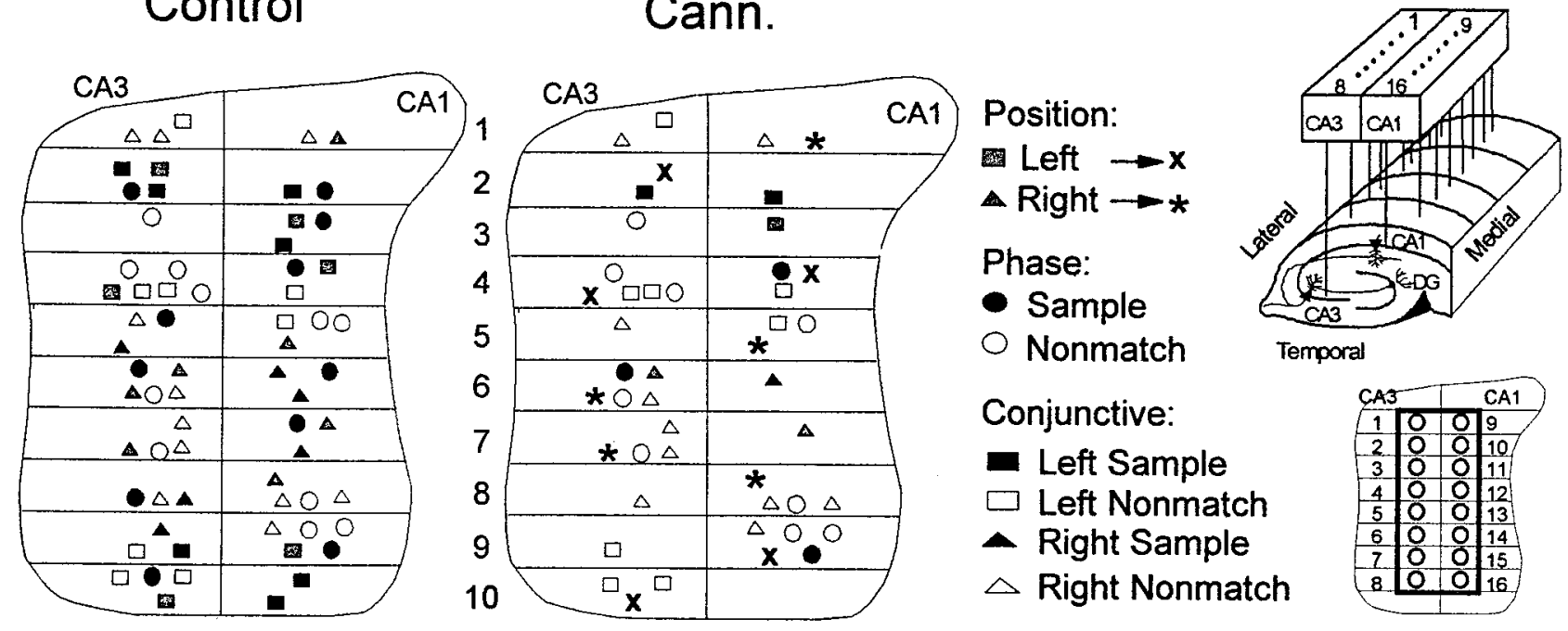

Conjunctive:

- Left Sample $\square$ Left Nonmatch

- Right Sample $\triangle$ Right Nonmatch

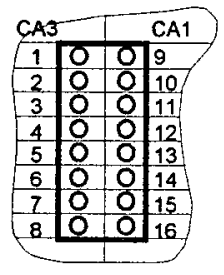

Figure 7. Anatomical distribution of hippocampal functional cell types. Neurons ( $n=67$ from 6 animals) were identified with respect to FCT and position on electrode recording array (top inset, right). the left panel depicts the identified anatomical location of position cells, phase cells, and conjunctive cells on a fold-out map of hippocampus with wire placement in the array noted at $200 \mu \mathrm{m}$ segments (bottom inset, right). Individual correlates are identified by shading and symbol coding as shown. The right panel depicts the distribution of FCTs after exposure to WIN-2 (0.35 mg/kg; Cann.) Note the loss of black shaded cells that fired during the sample phase; $*$ and $\times$ indicate control right and left position cells, respectively, which did not fire during the Sample phase in cannabinoid sessions but continued to fire during the appropriate Nonmatch phase. Only three sample phase cells and three left or right sample conjunctive cells continued to respond in the WIN-2 $(35 \mathrm{mg} / \mathrm{kg})$ sessions. There was no significant change in the distribution of phase or conjunctive cells that fired in the nonmatch phase. Insets, top, Diagram of hippocampal recording array; bottom, placement of electrode recording sites on a fold-out map of hippocampus; pairs of electrodes were positioned in CA3 and CA1 at $200 \mu \mathrm{m}$ intervals along longitudinal axis of hippocampus. See Hampson et al. (1999b) for details of alignment of ensembles.

(Figs. 2-4) reduced information content and increased the number of neurons required to encode the same information (Fig. $5 D, E$ ). All of the above were effects consistent with the delay-dependent performance deficit in the DNMS task produced by cannabinoid exposure.

The findings also confirm our previous observation that taskrelevant hippocampal neuronal activity in cannabinoid sessions is spared in the Nonmatch phase (Figs. 2-4), which indicates that firing in the Sample phase may be controlled by different synaptic inputs to the same neurons (Witter et al., 2000). This was supported by the fact that 10 of 13 left or right position cells retained firing correlates in the nonmatch phase of the task when firing was eliminated in the sample phase (Figs. 6, 7; Table 1), suggesting that CA1 and CA3 FCTs are activated by at least two distinctly different sets of afferent inputs, only one of which is cannabinoid-sensitive. However, the cannabinoid-insensitive firing that occurs in the nonmatch phase is nevertheless insufficient to maintain normal behavioral performance (Figs. 1, 3).

The present study expanded our original assessment (Heyser et al., 1993) to include characterization of firing changes across entire ensembles of simultaneously recorded hippocampal neurons, and established that cannabinoids reduce ensemble information content in a manner that requires significantly more neurons to encode the same information as in control sessions (Fig. 5D,E). The reduced information content was undoubtedly the result of selective loss of the FCTs that encode the SR (Fig. 6). The similarity to the loss in information content in less coherent ensembles (Fig. 5D) reinforces this observation.

Finally, it is significant to note that although cannabinoids seriously affected encoding of trial-specific information, the means by which this occurred did not involve changing the location of activated FCTs along the septotemporal axis of the hippocampus. Figure 7 indicates that, in general, fewer FCTs fired during cannabinoid sessions, but when they resumed firing in control sessions it was at the same locations, consistent with the above conclusion that a select population of FCTs with sample firing correlates were susceptible to cannabinoid influences. The fact that the location of the remaining unaffected FCTs, primarily nonmatch cells or cells encoding nonmatch information, did not change location within the hippocampus, again suggests a blockade of a selective set of afferent inputs containing sample information.

The above changes in sample encoding strength produced by cannabinoids prompted an examination of the overall strategic nature of DNMS performance (Hampson and Deadwyler, 1996). As shown in Figure $5 A$, trials with low ensemble firing rates during the sample phase of the task were at risk for errors if the animal encountered a long-delay trial. However, this was a dynamic process that changed from trial to trial and was directly dependent on behavioral outcome (correct or error). The top box in the chart shows that sample encoding was strong (i.e., sample FCTs fire with highest rates; Fig. 5) after either successful performance or errors that occurred on long-delay trials. Because encoding was maximal under that condition, performance on trials with any duration of delay between 1 and $30 \mathrm{sec}$ tended to be correct (Fig. 5A).

Paradoxically, however, if encoding of the sample was strong and the animal encountered a short-delay $(<15 \mathrm{sec})$ trial, the outcome, even though successful, was followed by a tendency for weaker encoding in the Sample phase on the next trial (Fig. 8A, Weak Code $b o x)$. If a short-delay trial was encountered, it was again likely to be performed successfully, but encoding strength continued to decrease on the next trial (Fig. 8 A, Weaker Code box). As the chart illustrates, the process continued in a downward cascade if short delay trials were repeated, ultimately resulting in an error due to weak encoding on a (just as probable) long-delay trial. This "subjective" encoding cascade is consistent with previous lesion studies, which showed that the hippocampus was not required if delays on trials were short $(\leq 5.0 \mathrm{sec})$ but became more and more relevant as delays increased (Hampson et al., 1999a). Such a cascade necessarily put the animal at risk for an error when strings of short-delay trials were encountered, because trial delays were determined at random. Once an error occurred, the Sample phase encoding strength was "reset" to maximal levels on the next trial.

The nature of this dynamic trial-to-trial interdependence of sample encoding strength and behavioral outcome was altered by cannabinoids and its associated selective reduction in FCT firing in the sample phase (Figs. 6, 7; Table 1). The link between long-delay correct and strong encoding on the next trial was broken (Fig. $8 B$, thin dashed arrow line) during cannabinoid sessions. However, the 
A. Control

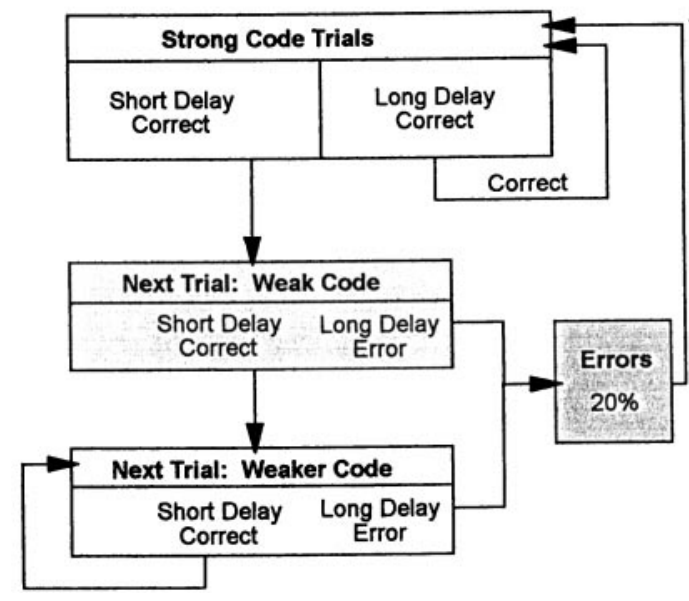

B. Cannabinoid

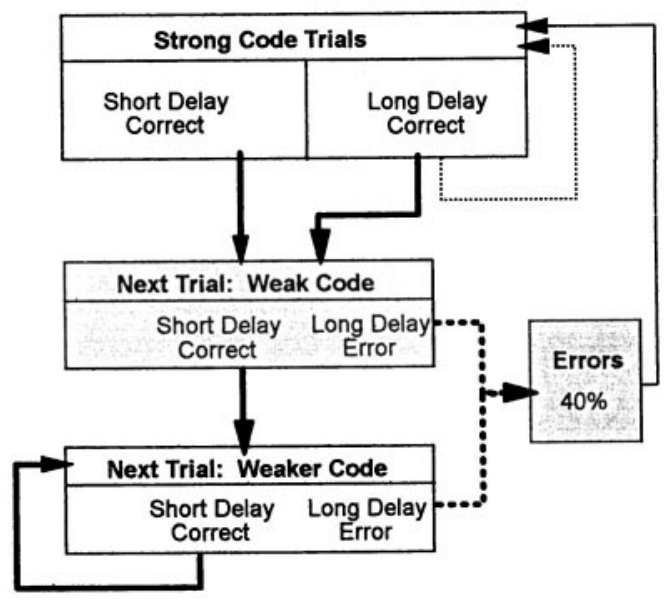

Figure 8. DNMS behavioral cascade depends on strength of sample phase encoding. $A$, Control. Cascade starts with strong encoding of SR on long-delay trials. The result will be a correct trial irrespective of delay. If delay is short, the following trial receives a weaker SR code. If a short-delay trial occurs again, the code strength is again reduced on the next trial. Correct performance on short-delay trials successively weakens the SR code, eventually leading to an error attributable to occurrence of an equally likely long-delay trial that incorporates a weak SR code. $B$, Cannabinoid exposure disrupts the ability to break the cascade influence (bold lines) by eliminating the strong codes after long-delay trials (dashed line). This increases the number of long-delay errors due to weaker codes after all correct trials.

minimum ensemble firing rate required for correct performance at a given delay was not changed by cannabinoids (Figs. $4 B, 5 B$ ).

The above results provided important insight into the dynamics of the memory processing in this task. Cannabinoids not only suppressed encoding of sample information but also prevented the adjustment of encoding strength as a function of performance outcome on the previous trial. If this is also true of humans who smoke marijuana and activate cannabinoid receptors in hippocampus and related areas, it is likely that much of the short-term memory deficit reported in these cases (Miller and Branconnier, 1983; Nahas and Latour, 1992; Hall et al., 1994; Pope and Yurgelun-Todd, 1996; Hall and Solowij, 1998) can be relegated to deficiencies in mechanisms of information encoding in the hippocampus. Information presented to subjects exposed to cannabinoids is not likely to be encoded correctly and as a consequence not likely to be accurately retrieved or recalled (Tulving and Markowitsch, 1997, 1998; Schacter and Wagner, 1999).

\section{REFERENCES}

Akinshola BE, Chakrabarti A, Onaivi ES (1999) In-vitro and in-vivo action of cannabinoids. Neurochem Res 24:1233-1240.

Angeli SJ, Murray EA, Mishkin M (1993) Hippocampectomized monkeys can remember one place but not two. Neuropsychologia 31:1021-1030.

Brodkin J, Moerschbaecher JM (1997) SR141716A antagonizes the disruptive effects of cannabinoid ligands on learning in rats. J Pharmacol Exp Ther 282:1526-1532.

Calignano A, La Rana G, Giuffrida A, Piomelli D (1998) Control of pain initiation by endogenous cannabinoids. Nature 394:277-281.

Chait LD, Pierri J (1992) Effects of smoked marijuana on human performance: a critical review. In: Marijuana/cannabinoids: neurobiology and neurophysiology (Murphy L, Bartke A, eds), pp 387-423. Boca Raton, FL: CRC.

Cho YH, Jaffard R (1995) Spatial location learning in mice with ibotenate lesions of entorhinal cortex or subiculum. Neurobiol Learn Mem 64:285-290.

Correll RE, Scoville WB (1965) Performance on delayed match following lesions of medial temporal lobe structures. J Comp Physiol Psychol 60:360-367.

Deadwyler SA, Hampson RE, Bennett BA, Edwards TA, Mu J, Pacheco MA, Ward SJ, Childers SR (1993) Cannabinoids modulate potassium current in cultured hippocampal neurons. Receptors Channels 1:121-134.

Deadwyler SA, Hampson RE, Childers SR (1995) Functional significance of cannabinoid receptors in brain. In: Cannabinoid receptors (Pertwee RG, ed), pp 205-231. London: Academic.

Deadwyler SA, Bunn T, Hampson RE (1996) Hippocampal ensemble activity during spatial delayed-nonmatch-to-sample performance in rats. J Neurosci 16:354-372.

Ferrari F, Ottani A, Vivoli R, Giuliani D (1999) Learning impairment produced in rats by the cannabinoid agonist HU 210 in a water-maze task. Pharmacol Biochem Behav 64:555-561.

Gochin PM, Colombo M, Dorfman GA, Gerstein GL, Gross CG (1994) Neural ensemble coding in inferior temporal cortex. J Neurophysiol 71:2325-2337.

Hall W, Solowij N (1998) Adverse effects of cannabis. Lancet 352:1611-1616.

Hall W, Solowij N, Lemon J (1994) The health and psychological consequences of cannabis use. Canberra, Australia: Australian Government Public Service.

Hamming RW (1986) Coding and information theory. Englewood Cliffs, NJ: Prentice-Hall.

Hampson RE, Deadwyler SA (1996) Ensemble codes involving hippocampal neurons are at risk during delayed performance tests. Proc Natl Acad Sci USA 93:13487-13493.

Hampson RE, Deadwyler SA (1998a) Role of cannabinoid receptors in memory storage. Neurobiol Dis Exp Neurol B 5:474-482.

Hampson RE, Deadwyler SA (1998b) Methods, results and issues related to recording neural ensembles. In: Neuronal ensembles: strategies for recording and decoding (Eichenbaum H, Davis J, eds), pp 207-234. New York: Wiley.

Hampson RE, Deadwyler SA (1999) Cannabinoids, hippocampal function and memory. Life Sci 65:715-723.

Hampson RE, Deadwyler SA (2000) Differential information processing by hippocampal and subicular neurons. In: The parahippocampal region: special supplement to the Annals of the New York Academy of Sciences (Witter MP, ed), New York: New York Academy of Sciences.

Hampson RE, Heyser CJ, Deadwyler SA (1993) Hippocampal cell firing correlates of delayed-match-to-sample performance in the rat. Behav Neurosci 107:715-739.

Hampson RE, Byrd DR, Konstantopoulos JK, Bunn T, Deadwyler SA (1996) Hippocampal place fields and spike-train correlation: relationship between degree of place field overlap and cross-correlation. Hippocampus 6:281-293.

Hampson RE, Rogers G, Lynch G, Deadwyler SA (1998) Facilitative effects of the ampakine CX516 on short-term memory in rats: correlations with hippocampal ensemble activity. J Neurosci 18:2748-2763.

Hampson RE, Jarrard LE, Deadwyler SA (1999a) Effects of ibotenate hippocampal and extrahippocampal destruction on delayed-match and -nonmatch-to-sample behavior in rats. J Neurosci 19:1492-1507.

Hampson RE, Simeral JD, Deadwyler SA (1999b) Distribution of spatial and nonspatial information in dorsal hippocampus. Nature 402:610-614.

Herkenham M, Lynn AB, Little MD, Johnson MR, Melvin LS, de Costa BR, Rice KC (1990) Cannabinoid receptor localization in brain. Proc Natl Acad Sci USA 87:1932-1936.

Heyser CJ, Hampson RE, Deadwyler SA (1993) The effects of delta-9THC on delayed match to sample performance in rats: alterations in short-term memory produced by changes in task specific firing of hippocampal neurons. J Pharmacol Exp Ther 264:294-307.

Hoffman AF, Lupica CR (2000) Mechanisms of cannabinoid inhibition of GABA-A synaptic transmission in the hippocampus. J Neurosci 20:2470-2479. 
Jarrard LE (1993) On the role of the hippocampus in learning and memory in the rat. Behav Neural Biol 60:9-26.

Katona I, Sperlagh B, Sik A, Kafalvi A, Vizi ES, Mackie K, Freund TF (1999) Presynaptically located CB1 cannabinoid receptors regulate GABA release from axon terminals of specific hippocampal interneurons. J Neurosci 19:4544-4558.

Lichtman AH, Martin BR (1996) Delta 9-tetrahydrocannabinol impairs spatial memory through a cannabinoid receptor mechanism. Psychopharmacology 126:125-131.

Lichtman AH, Dimen KR, Martin BR (1995) Systemic or intrahippocampal cannabinoid administration impairs spatial memory in rats. Psychopharmacology 119:282-290.

Mackie K, Hille B (1992) Cannabinoids inhibit N-type calcium channels in neuroblastoma-glioma cells. Proc Natl Acad Sci USA 89:3825-3829.

Mallet PE, Beninger RJ (1998) The cannabinoid CB1 receptor antagonist SR141716A attenuates the memory impairment produced by delta 9-tetrahydrocannabinol or anandamide. Psychopharmacology 140:11-19.

Miller LL, Branconnier RJ (1983) Cannabis: effects on memory and the cholinergic limbic system. Psychol Bull 93:441-456.

Milner B (1972) Disorders of learning and memory after temporal lobe lesions in man. Clin Neurosurg 19:421-446.

Mishkin M, Vargha-Khadem F, Gadian DG (1998) Amnesia and the organization of the hippocampal system. Hippocampus 8:212-216.

Misner DL, Sullivan JM (1999) Mechanism of cannabinoid effects on long-term potentiation and depression in hippocampal CA1 neurons. J Neurosci 19:6795-6805.

Nahas G, Latour C (1992) The human toxicity of marijuana. Med J Aust 156:495-497.

Nakamura-Palacios EM, Moerschbaecher JM, Barker LA (2000) The pharmacology of SR141716A: a review. CNS Drug Rev 5:43-58.

Olton DS, Feustle WA (1981) Hippocampal function required for nonspatial working memory. Exp Brain Res 41:380-389.

Parkinson JK, Murray EA, Mishkin M (1988) A selective mnemonic role for the hippocampus in monkeys: memory for the location of objects. J Neurosci 8:4159-4167.

Pope Jr HG, Yurgelun-Todd D (1996) The residual cognitive effects of heavy marijuana use in college students. JAMA 275:521-527.

Raffaele KC, Olton DS (1988) Hippocampal and amygdaloid involvement in working memory for nonspatial stimuli. Behav Neurosci 102:349-355.

Rawlins JN, Lyford GL, Seferiades A, Deacon RM, Cassaday HJ (1993) Critical determinants of nonspatial working memory deficits in rats with conventional lesions of the hippocampus or fornix. Behav Neurosci 107:420-433.
Rawlins JNP (1985) Associations across time: the hippocampus as a temporary memory store. Behav Brain Sci 8:479-528.

Reibaud M, Obinu MC, Ledent C, Parmentier M, Bohme GA, Imperato A (1999) Enhancement of memory in cannabinoid CB1 receptor knock-out mice. Eur J Pharmacol 379:R1-R2.

Rinaldi-Carmona M, Barth F, Heaulme M, Shire D, Calandra B, Congy C, Martinez S, Marauni J, Neliat G, Caput D, Ferrara P, Soubrie P, Breliere JC, LeFur G (1994) SR141716A, a potent and selective antagonist of the brain cannabinoid receptor. FEBS Lett 350:240-244.

Schacter DL, Wagner AD (1999) Medial temporal lobe activation in fMRI and PET studies of episodic encoding and retrieval. Hippocampus 9:7-24.

Scoville WB, Milner B (1957) Loss of recent memory after bilateral hippocampal lesions. J Neurol Neurosurg Psychiatry 20:11-12.

Shen M, Piser TM, Seybold VS, Thayer SA (1996) Cannabinoid receptor agonists inhibit glutamatergic synaptic transmission in rat hippocampal cultures. J Neurosci 16:4322-4334.

Stevens J (1992) Applied multivariate statistics for the social sciences. Hillsdale, NJ: Lawrence Erlbaum Associates.

Terranova JP, Storme JJ, Lafon N, Perio A, Rinaldi-Carmona M, Le Fur G, Soubrie P (1996) Improvement of memory in rodents by the selective CB1 cannabinoid receptor antagonist, SR 141716. Psychopharmacology 126:165-172.

Tsou K, Brown S, Sanudo-Pena MC, Mackie K, Walker JM (1998) Immunohistochemical distribution of cannabinoid CB1 receptors in the rat central nervous system. Neuroscience 83:393-411.

Tulving E, Markowitsch HJ (1997) Memory beyond the hippocampus. Curr Opin Neurobiol 7:209-216.

Tulving E, Markowitsch HJ (1998) Episodic and declarative memory: role of the hippocampus. Hippocampus 8:198-204.

Twitchell W, Brown S, Mackie K (1997) Cannabinoids inhibit N- and $\mathrm{P} / \mathrm{Q}$-type calcium channels in cultured rat hippocampal neurons. J Neurophysiol 78:43-50.

Warrington EK, Duchen LW (1992) A re-appraisal of a case of persistent global amnesia following right temporal lobectomy: a clinico-pathological study. Neuropsychologia 30:437-450.

Witter MP, Wouterloud FG, Naber PA, Haeften TV (2000) Anatomical organization of the parahippocampal-hippocampal network. In: The parahippocampal region (Scharfman H, Witter MP, Schwartz R, eds), pp 1-24. New York: New York Academy of Sciences.

Zola-Morgan S, Squire LR, Amaral DG (1986) Human amnesia and the medial temporal region: enduring memory impairment following a bilateral lesion limited to field CA1 of the hippocampus. J Neurosci 6:2950-2967. 